IZA DP No. 9064

Global Poverty Goals and Prices: How Purchasing Power Parity Matters

Dean Jolliffe

Espen Beer Prydz

May 2015 


\title{
Global Poverty Goals and Prices: How Purchasing Power Parity Matters
}

\author{
Dean Jolliffe \\ World Bank, \\ IZA and NPC \\ Espen Beer Prydz \\ World Bank
}
Discussion Paper No. 9064
May 2015

\author{
IZA \\ Germany
}

P.O. Box 7240

53072 Bonn

Phone: +49-228-3894-0

Fax: +49-228-3894-180

E-mail: iza@iza.org

Any opinions expressed here are those of the author(s) and not those of IZA. Research published in this series may include views on policy, but the institute itself takes no institutional policy positions. The IZA research network is committed to the IZA Guiding Principles of Research Integrity.

The Institute for the Study of Labor (IZA) in Bonn is a local and virtual international research center and a place of communication between science, politics and business. IZA is an independent nonprofit organization supported by Deutsche Post Foundation. The center is associated with the University of Bonn and offers a stimulating research environment through its international network, workshops and conferences, data service, project support, research visits and doctoral program. IZA engages in (i) original and internationally competitive research in all fields of labor economics, (ii) development of policy concepts, and (iii) dissemination of research results and concepts to the interested public.

IZA Discussion Papers often represent preliminary work and are circulated to encourage discussion. Citation of such a paper should account for its provisional character. A revised version may be available directly from the author. 


\section{ABSTRACT \\ Global Poverty Goals and Prices: How Purchasing Power Parity Matters}

With the recent release of the 2011 purchasing power parity (PPP) data from the International Comparison Program (ICP), analysts and institutions are confronted with the question of whether and how to use them for global poverty estimation. The previous round of PPP data from 2005 led to a large increase in the estimated number of poor in the world. The 2011 price data suggest that developing countries' incomes in PPP-adjusted dollars are significantly higher than indicated by the 2005 PPP data. This has created the anticipation that the new PPP data will decrease significantly the count of poor people in the world. This paper presents evidence that if the global poverty line is updated with the 2011 PPP data based on the same set of national poverty lines that define the \$1.25 line in 2005 PPPs, and if the 2011 PPP conversion factors are used without adjustments to selected countries, the 2011 poverty rate is within half a percentage point of the current global estimate based on 2005 PPPs. The analysis also indicates that the goal of 'ending' extreme poverty by 2030 continues to be an ambitious one.

JEL Classification: I3, I32, E31, F01

Keywords: $\quad$ global poverty, International Comparisons Program, purchasing power parity

Corresponding author:

Dean Jolliffe

The World Bank

1818 H Street NW

Mail Stop MC10-1004

Washington, DC 20433

USA

E-mail: djolliffe@worldbank.org

\footnotetext{
* Please note that this paper does not reflect official estimates of the World Bank Group. The authors wish to thank participants of a "Global Poverty Monitoring and the 2011 ICP Purchasing Power Parity Indices" workshop, and seminar participants from the World Bank's Poverty Global Practice for useful feedback. They also thank Aziz Atamanov, Shaohua Chen, Andrew Dabalen, Aslı Demirgüç-Kunt, Yuri Dikhanov, Francisco H.G. Ferreira, Nada Hamadeh, Aart Kraay, Christoph Lakner, Peter Lanjouw, Martin Ravallion, Umar Serajuddin, Prem Sangraula and Tara Vishwanath for helpful conversations, comments and advice. The analysis in this paper is based on the publicly available data from the World Development Indicators database and PovcalNet, which is a World Bank research product led by Shaohua Chen.
} 


\section{Introduction}

Should changing price levels across countries affect the overall count of poor people in the world? If so, how should the new data on price levels across the world be incorporated into global poverty estimates? These questions have prompted intense disagreement within the international development community. The disagreement is not without good reason - the share of people living in extreme poverty has become one of the most prominent indicators for assessing progress in global economic development. It has been a central indicator for the Millennium Development Goals and is emerging as an important indicator among the Sustainable Development Goals. The World Bank (2013) recently announced a new goal of the institution to reduce the share of the world's population living in extreme poverty to no more than 3 percent by 2030. Moreover, many other international organizations and bilateral development actors are focusing their efforts on reducing and, ultimately, ending extreme poverty, as defined by the international poverty line. These global goals and targets have been based on an understanding of the current level of global poverty based on prices as measured by the 2005 purchasing power parity (PPP) data and the poverty line of $\$ 1.25$. Therefore, large revisions to the global profile and rate of poverty as a result of integrating the 2011 PPP measures of country-level prices may cause confusion and undermine the confidence in the poverty indicator and also the associated goals.

In 2014, the International Comparison Program (ICP) released an update to the PPP data based on an extensive data collection effort to measure price differences across the globe. ${ }^{1}$ The resulting PPP conversion factors for 2011 were immediately integrated into the World Bank’s World Development Indicators (WDI) database and applied to key macroeconomic indicators, such as GDP and other national accounts variables, replacing all indicators based on the 2005

\footnotetext{
${ }^{1}$ See World Bank (2014b).
} 
ICP round. The PPP conversion factors have also historically been used by the World Bank for constructing estimates of global poverty. In principle, the approach used by the World Bank to estimate global poverty is to estimate a fixed benchmark (or poverty line) denominated in PPP US dollars and then convert this value into local currencies based on the PPP conversion factor to ensure that the value of the poverty line represents approximately the same standard of living across the world. ${ }^{2}$ In essence, the PPP conversion factors are the exchange rates used to keep the real value of the poverty line the same across all countries. ${ }^{3}$

PPP data though are only collected sporadically and with changes to methodologies, which can result in jarring changes to the estimated relative cost of living across countries with the release of new PPP data. ${ }^{4}$ Between 2005 and 2011 there were no new PPP data collected for developing countries, but many global indicators are nonetheless reported annually in PPP terms. One method for handling the interim years followed by the World Development Indicators is to estimate extrapolated PPP conversion factors by the relative rates of inflation between the United States (U.S.) and the local country. Global poverty estimates do not directly use the extrapolated PPP estimates, but follow an approach that is conceptually equivalent to using the extrapolations. Specifically, the current value of consumption in local currency is brought back or forward to the relevant PPP benchmark year (e.g. 2005 or 2011) by the national consumer price index (CPI) and

\footnotetext{
${ }^{2}$ For a more detailed description of how the poverty line is estimated, see Jolliffe et al. (2014). The PPP conversion factors used for poverty estimates are those estimated for household final consumption expenditure. The data is available from ICP at http://icp.worldbank.org/icp/GlobalResult.aspX and through the WDI.

${ }^{3}$ And, in contrast to using market currency exchange rates, Deaton (2005) notes that "Making comparisons in PPP units corrects, or at least diminishes, the gross understatement of living standards in poor countries relative to rich ...” (p. 2)

${ }^{4}$ The ICP was started in 1968 as a collaborative effort of the United Nations Statistical Division (UNSD) and the University of Pennsylvania and the first round of ICP data were collected in 1970, covering 10 countries. Subsequent rounds of the ICP occurred on an occasional basis. Between 1970 and 2013, there have been eight rounds of ICP data collection with the coverage of countries increasing from 10 countries to 199 countries in the most recent 2011 round of data collection. For more discussion of the history of the ICP, see http://go.worldbank.org/WLPETUYSO0 or Jolliffe et al. (2014).
} 
then the benchmark year PPP conversion factor is applied to obtain the PPP US dollar value of consumption. The poor are then identified as those whose consumption (or income for some countries) in PPP US dollars is less than the global extreme poverty line, currently set at 1.25 in 2005 PPP US dollars.

This approach of using the national CPI to bring all consumption values to a common date is considered to be an approximate method for capturing changing relative price levels across countries. If it performs well, there should not be sharp changes in poverty rates with the release of new PPP data, but historically this has not been the case. For example, when the 2005 PPP data were released, Chen and Ravallion (2010) re-estimated the global poverty line and headcount based on adjusted 2005 PPP data and observed significant changes in the poverty line and average value of consumption (relative to expectations based on the extrapolated PPP adjustment factors from the 1993 PPPs). Both of these changes resulted in Chen and Ravallion's assessment that the new price data indicated that past estimates of global poverty needed to be adjusted upwards by 500 million persons. Nothing had changed to the standard of living of the poor overnight, but the belief was that the 2005 PPP data provided a better assessment of relative prices than the previous PPP factors (scaled annually by the ratio of inflation rates).

Table 1 replicates a table from Deaton (2005) that presents three very different profiles of global poverty in 1993, each produced from different rounds of PPP data. For example, shifting from the 1985 PPP data to the 1993 PPP data led to a 35 percent decline in poverty in Latin America and a 27 percent increase in poverty in Sub-Saharan Africa for 1993. Similarly, shifting from the 1993 PPP data to the 2005 PPP conversion factors doubled the estimated rate of poverty in East Asia and the Pacific, and increased the headcount by half a billion people for 1993. In 
each case, the use of different PPP conversion factors produced a significant re-alignment of the regional profile of poverty.

The release of the 2011 PPP data places us once again in the position that new PPP data are changing our perception of global poverty. The 2011 data suggest that developing countries' incomes in PPP-adjusted dollars are significantly higher than indicated by the 2005 data. This has created the anticipation that new PPP data would lead to a large decrease in the global count of poor in the world. To highlight the change, commentators in the press and bloggers seem to now be making the erroneous assertion that adopting the new PPP data will extract millions of people from poverty overnight. ${ }^{5}$ Their true standard of living is unchanged whether the 2011 PPP data are used or not. The issue is whether the new PPP data improve the correct assessment of who is poor, as judged on a common threshold for cross country comparisons. Of course, for the World Bank and other international organizations, this is not purely an analytical exercise but issues of communication are also concerns.

The presumptive trade-off is to use the new PPP data and run the risk of being perceived as conveniently manipulating the data to achieve the poverty goal, or break the methodological approach in how the poor are counted in order to keep the target as challenging to reach as when the 3 percent goal was announced. However, our analysis suggests that this concern may be a false trade-off. This paper presents evidence that if the global poverty line based on the 2011 PPP data is re-estimated based on the same set of national poverty lines that define the $\$ 1.25$ line in 2005 PPPs, the revised 2011 global count of the extreme poor increases slightly, and the path to ending poverty by 2030 continues to be ambitious.

\footnotetext{
${ }^{5}$ These assertions are presumably not intended to be taken at face-value, but are made to purposely highlight how sensitive our understanding of poverty rates is to underlying data and assumptions.
} 
The rest of this paper proceeds as follows: Section 2 presents a limited literature review that assesses the quality of the 2011 PPP data and discusses the urban-bias adjustment used for poverty estimation based on the 2005 PPP data. Section 3 first describes our approach to estimating a revised, methodologically consistent and comparable poverty line for 2011, and then presents an alternative poverty line that addresses sensitivity concerns of the existing methodology. Section 4 provides our analysis of the implications of using the 2011 PPP data on re-estimated profiles of global poverty. This section also essentially replicates the poverty projections presented in Jolliffe et al. (2014) but based on the 2011 PPP data and shows what the projected path of poverty to 2030 looks like. Section 5 presents some concluding discussion.

\section{Assessments of the 2011 PPP Data and Implications for Global Poverty}

Reactions to the release of the 2011 PPP data have been varied, ranging from the view that these data reflect an unambiguous improvement over the 2005 data (World Bank, 2015) to a view that seems to suggest that they are sufficiently problematic that they should not be used for global poverty measurement.

\section{A. Comparisons of the 2005 and 2011 PPP Data}

Deaton and Aten (2014) believe that the 2011 PPP data are superior to the 2005 PPP data, and in part reverse an error in the 2005 PPP estimates. The 2005 PPP data are essentially the product of two price indices - one index established purchasing power parity within regions and the other established a price index across regions. The cross-region index is based on data from a set of 18 so-called "ring" countries in which a distinct commodity list was used to price out goods that were not unique to any particular region. Deaton and Aten argue that the cross-region ring index 
is the key source of error in the 2005 PPP data resulting in an overestimation of the price levels in Africa, Asia and Western Asia by 20 to 30 percent.

Findings from Ravallion (2014) lead to almost the opposite interpretation, suggesting that there are potentially significant concerns about the 2011 PPP data. He argues that the downward drift in prices observed for much of Asia (but not China) is in contrast to what would be expected given the observed rate of economic growth. A part of his interpretation of the data rests on the dynamic Penn Effect (Ravallion, 2013) which suggests that the ratio of the PPP index to the market exchange rate rises with economic growth. Ravallion offers a hypothesis that over time the bundle of goods used for the PPP index has become more heavily weighted towards internationally traded goods (for which prices exist) and this has led to a downward shift in price levels relative to market exchange rates (conditioning on growth rates).

Inklaar and Rao (2014) start from noting that the concern over the 2011 PPP data is primarily driven by the large difference between estimated average income levels based on the 2011 data and the same averages based on extrapolations of the 2005 PPP data. Indeed, income and consumption levels are about 24 percent greater on average when using the 2011 PPP data, suggesting that the world is much richer than extrapolations of the 2005 PPP data led us to expect. Their objective is to try to understand how much of this difference is due to the underlying data and how much is the result of the methodology used to create the PPP index. They note that the ICP introduced many initiatives to improve the data quality with the 2011 exercise, including the changed approach for handling ring countries.

Using the unprocessed, unit-record price data, Inklaar and Rao re-construct the 2005 PPP index following the same methodology that was used for the 2011 PPP index. This step alone reduces the divergence between mean consumption from about 24 percent to about 18 percent. 
They then argue that they identify a bias in the 2005 data in terms of the product list for ring countries. Their adjustment for this bias further reduces the difference to about 9 to 12 percent. Applying both the harmonized methodology and the bias correction simultaneously reduces the 24 percent difference in mean consumption to somewhere between 4 and 10 percent (depending on the measure considered). The latter bias correction can be viewed as a mix of data quality and methodology issues, but their analysis reveals that the lack of a harmonized method across the two PPP indices is one significant explanation for the difference. In this light, Inklaar and Rao can be interpreted as viewing the 2011 PPP index as an improvement over the 2005 index. ${ }^{6}$

\section{B. Initial Poverty Estimates Based on the 2011 PPP Data}

That there is now much attention to the 2011 PPP index and, more generally, the importance of price adjustments to global poverty measurement can be largely attributed to the provocative and useful blogs by Chandy and Kharas (2014) and Dykstra, Kenny, and Sandefur (2014). Immediately after the release of the 2011 PPP data, Dykstra, Kenny and Sandefur estimated that in 2010, the share of people in the developing world living below the $\$ 1.25$ per day poverty line declined from 19.7 percent to 8.9 percent "overnight". ${ }^{7}$ Chandy and Kharas (2014) follow an approach similar in spirit (though differing in the details) to the methodology used in Chen and Ravallion (2010) and re-estimate the poverty line accounting for changes in local price levels. They provide several candidate estimates of the count of the poor, but hone in on an estimate where the number of poor declines by about 300 million from using the 2011 PPP data (rather than the 2005 PPP data when estimating the number of poor in 2010).

\footnotetext{
${ }^{6}$ It is useful to also note that the question is not whether the 2005 PPP index is of better or worse quality than the 2011 PPP index, but rather whether the combination of the 2005 PPP index and the extrapolation methodology (based on inflation rates) outperforms the new 2011 PPP data.

${ }^{7}$ Their methodological approach is to adjust the $\$ 1.25$ poverty line, which is denominated in 2005 USD, to 2011 by using the U.S. inflation rate. This adjustment brings their poverty line to a value of $\$ 1.44$ in 2011 USD. This methodology differs significantly from the approach followed by Chen and Ravallion (2010) and described in Jolliffe et al. (2014) for setting an international poverty line.
} 
The timely analyses of Chandy and Kharas, and Dykstra, Kenny and Sandefur certainly suggest that the 2011 PPP data have a significant effect on the global profile of poverty. An important aspect of both though is that because they are extracting data from PovcalNet in 2005 PPP dollars their analyses implicitly embed an adjustment for urban-bias that was estimated based on analysis of the 2005 PPP data. ${ }^{8}$ Chen and Ravallion (2010) argue that the 2005 PPP required rural-urban adjustments for China, India and Indonesia. This was done for good reasons. For example, Chen and Ravallion (2008) note that the 2005 ICP survey in China was confined to only 11 cities and therefore they view the ICP 2005 PPP as an urban PPP index for China. To correct for this, they use the ratio of urban to rural national poverty lines to provide a scaling factor to scale rural consumption such that it is expressed in urban price levels. ${ }^{9}$ This adjustment alone reduced poverty in China by nearly half in 2005, from 26.4 percent to 15.6 percent. They argue that there is also reason to believe that the 2005 PPP data for India contain an urban bias and make similar adjustments. For Indonesia, a similar adjustment is made to adjust for differences in rural and urban price levels, but not primarily due to suspected bias in the 2005 ICP price collection. ${ }^{10}$

In PovcalNet, rather than directly adjusting the PPP conversion factors to the rural and urban income distributions, the adjustments are built into the displayed consumption values. For the purposes of estimating the count of the poor, adjusting either the PPP or consumption data

\footnotetext{
${ }^{8}$ PovcalNet is perhaps the most commonly used data tool for estimating global poverty counts. It is an online tool, maintained by the World Bank, which allows analysts to specify parameter values such as the global poverty line, and then estimate the number of poor people in the world based on their assumptions. For more details, see: http://iresearch.worldbank.org/PovcalNet/index.htm.

${ }^{9}$ National poverty lines used in this analysis represent the cost of obtaining basic needs. Within-country differences in poverty lines therefore reflect, in principle, both differences in prices and needs (most typically through the nonfood allowance).

${ }^{10}$ There are also other countries that have adjustments for urban bias built in. Much of the data in PovcalNet from the Latin America region draws from the SEDLAC database which scales up all rural values by 15 percent to account for urban-rural price differences (http://sedlac.econo.unlp.edu.ar/eng/methodology_faqs.php?page=2).
} 
has the equivalent effect. But, when making this adjustment directly in PovcalNet, users of the data obtain PPP denominated values that have urban-bias adjustments built in. If producing poverty estimates using the 2005 PPP data, and wishing to follow the methodology of Chen and Ravallion (2010), then these are the correct values to use. But, once the analysis shifts to the 2011 PPP data, using these adjustments only makes sense if the analysts wishes to assume that the data continue to need a correction for urban bias and that the magnitude of this adjustment is the same as in $2005 .^{11}$

To date, there is no evidence that the particular adjustments that were made to the 2005 PPP data should be carried over to the 2011 PPP data. Even if evidence points to an urban bias in some countries in the 2011 ICP round, there is no reason to assume that the correction based on the 2005 PPP data is the correct adjustment to be used in the 2011 data. ${ }^{12}$ In contrast, the report of the International Comparison Program (World Bank, 2015) suggests that data from the 2011 ICP round was much better at capturing rural prices than the 2005 ICP round, particularly with respect to China, India and Indonesia -- three large-population countries in Asia where there was particular concern about urban bias.

For example, the Asian Development Bank (2014) reports that the 2011 ICP saw the full and complete participation of China, accomplishing national coverage with price collection in over 30 provinces, including rural and urban areas with only 8 percent of the collection points being from large shops. This stands in stark contrast to the 11 cities included in the 2005 round. World Bank (2015, p.3) further states that for India and Indonesia the 2011 ICP “also achieved coverage of both rural and urban areas in their collection of prices.” In the case of Indonesia,

\footnotetext{
${ }^{11}$ Not all researchers were in agreement about the validity of these adjustments to the data. Deaton and Heston (2010), both of whom served on the ICP technical advisory board, argue that the 2005 PPP index almost certainly underestimated the price level in China by at least 20 percent.

${ }^{12}$ Adjustments may have to be made to the 2011 data, but it is difficult to know how because sampling data for the ICP data are not readily available for a number of countries.
} 
price data were collected from 2,645 outlets in rural and urban areas of which only 3 percent were large shops (World Bank, 2014b). ${ }^{13}$ While we recognize that any sampling bias in collection of PPP data is a concern, and further work should be done to assess this, we argue there is no valid reason to maintain the same bias adjustments in the 2011 PPPs as used in the 2005 PPPs.

For the purposes of this paper, we remove the urban-rural adjustments for China, India and Indonesia embedded in the data obtained from PovcalNet. ${ }^{14}$ When we remove these urban-rural adjustments from the analysis, we refer to this as using the 2011 PPP at "face value”. For the sake of comparison, we also carry out the analysis in some cases with the adjustments left in the data and refer to these results as the 2011 PPP adjusted estimates. Our analysis does not directly assess the relative quality of the 2005 PPP data as compared to the 2011 PPP data, but rather aims to show how the use of the 2011 PPP data affects the global profile of poverty and poverty projections.

\section{Setting a Global Poverty Line with 2011 PPPs}

In order to estimate the level and trends in global poverty based on the various PPPs described above, it is necessary to first define the value of the global poverty line. For estimates based on the 2005 PPP data, we use the same $\$ 1.25$ per person per day (in 2005 PPP units) as used by the World Bank (2014a) and many other international organizations. However, for analysis of global extreme poverty using the 2011 PPPs, we need to define a poverty line denominated in 2011

\footnotetext{
${ }^{13}$ Based on background metadata from World Bank (2014b).

${ }^{14}$ All of the analysis of the 2011 profile of poverty draws only from published articles and publicly available PovcalNet data. In particular, the underlying data are based on extracting survey means and decile shares (which are publicly available in PovcalNet) to estimate consumption, or in some cases income Lorenz curves. The analysis of the poverty line is based on poverty lines from published data and using the World Development Indicators data to obtain PPP and CPI data. More details on the construction of the data files and on the removal of the urban-bias adjustment are available in Annex 1.
} 
PPPs comparable to the $\$ 1.25$ line in 2005 PPPs. .

\section{A. Updating the Global Poverty Line - A Fixed Goal Line}

One suggested method for updating the $\$ 1.25$ poverty line is to simply update it by US inflation over time, so that the real value of the poverty line remains the same in the US. Between 2005 and 2011, there was about 15.2 percent inflation in the US, so adjusting the $\$ 1.25$ poverty line by inflation results in a new poverty line of \$1.44 in 2011 terms. Following this approach, the global poverty line would buy the same basket of goods in the US over time. To convert this into local currencies in 2011, we would simply apply the 2011 PPP conversion factor for private consumption from the ICP 2011. This is the method applied by Dykstra et al (2014) soon after the 2011 PPPs were first released and which led to a dramatic decrease in their estimated count of the extreme poor.

Despite reflecting the same real value in the US, the inflation-adjusted \$1.44 line converted using the 2011 PPPs translates into a lower value than the $\$ 1.25$ at 2005 PPPs, in the vast majority of national currencies.. The 2011 \$1.44 line buys the same basket of goods in the US as the $2005 \$ 1.25$ line. However, the \$1.44 line converted to national currencies at 2011 PPPs buys significantly fewer goods in most developing countries of the world than the \$1.25 line converted at 2005 PPPs. ${ }^{15}$ The price levels in most developing countries relative to the US were found to be much lower in the ICP 2011 round compared to the 2005 round. ${ }^{16}$ Figure 1 reveals that $\$ 1.44$ falls significantly below the 2011 mean value of poverty lines of the 15 countries that were used to establish the $\$ 1.25$ line. Therefore, a US-inflation based approach for updating the international poverty line is in contradiction to the principle that the global poverty line should reflect the national definitions of poverty of the poorest countries in the world.

\footnotetext{
${ }^{15}$ In other words, converting the $\$ 1.44$ into national currencies using the 2011 PPPs results in a lower value of the poverty line in most local currency values than a 1.25 line at 2005 PPPs.

${ }^{16}$ Price level in this case is defined as the ratio of the PPP exchange rate to the market exchange rate.
} 
While the methods have varied somewhat over the last 25 years, the common guiding principle has been that the global extreme poverty line should reflect how the world's poorest countries estimate a minimum threshold of living which meets basic needs. National poverty lines - set in the country context and in local currencies - give a good indication of each country's own definition of monetary poverty and have therefore been used as a guide in setting an international poverty line. Moreover, past studies have found that national poverty lines vary considerably and tend to increase with national per capita income. However, among the poorest countries, there appears to be little correlation between poverty lines and mean income levels (World Bank, 1990; Ravallion, Datt and van de Walle, 1991; Ravallion, Chen and Sangraula, 2009). This finding has been taken to suggest that for this set of countries, poverty lines may be reflective of some absolute cost of basic needs, a threshold which the international poverty line also should represent.

The method for quantifying the threshold that reflects the poverty lines of the world's poorest countries has varied across past studies, as described in Jolliffe et al. (2014). The most recent approach that resulted in the $\$ 1.25$ global poverty line is based on taking the average of the 2005 PPP equivalents of the national poverty lines of the world's 15 poorest economies in a sample of 75 national poverty lines. ${ }^{17}$ The group of 15 countries was identified through a review of several alternative methods that sought to select the set of countries where there is no relationship between national poverty lines and income, thereby maintaining the principle of estimating a poverty line based the poorest countries' evaluation of the cost of basic needs.

As our initial benchmark, we aim to keep the method and data as consistent as possible with the $\$ 1.25$ line that was established by Ravallion, Chen and Sangraula (2009). To this end, we set an international poverty line based on the same 15 national poverty lines that defined the

\footnotetext{
${ }^{17}$ See Ravallion, Chen and Sangraula (2009) for details.
} 
\$1.25 line. Table 2 shows the national poverty lines for the 15 countries converted to USD in both 2005 and 2011 PPPs. The mean value of these lines is \$1.25 in 2005 PPPs and \$1.82 in 2011 PPPs. ${ }^{18}$ Figure 1 plots these values and shows that $\$ 1.82$ reflects a comparable average cost of basic needs for these 15 countries in 2011 PPPs as the $\$ 1.25$ line did in 2005 PPPs. ${ }^{19}$ For the purpose of this initial benchmark, our aim is to keep the real value of the poverty line constant for those countries that served as the basis for defining the 2005 poverty line. An important motivation for this benchmark is that global poverty goals for 2030 were announced based on the $\$ 1.25$ poverty line, and the $\$ 1.82$ line is our estimate of the value which keeps the goal line fixed. That is to say that, on average, among the 15 poor countries that defined the $\$ 1.25$ line, $\$ 1.82$ at 2011 PPPs allows one to buy in 2011 the same bundle of goods in as \$1.25 did in 2005 at 2005 PPPs.

A higher poverty line of $\$ 2.00$ per day in 2005 PPPs is also commonly reported by the World Bank, especially for comparative analysis of poverty in middle-income countries, although it is not used for monitoring of global poverty goals. This line was used by Chen and Ravallion (2010) and corresponds to the median value of the sample of national lines used by Ravallion, Chen and Sangraula (2008) to derive the \$1.25 line. The median value of the same sample of lines in 2011 PPPs is $\$ 3.08$ and we therefore consider this as the comparable line to the $\$ 2.00$ line in 2005 PPPs.

\footnotetext{
${ }^{18}$ An earlier version of this paper gave estimates of $\$ 1.70$ as the average of the national poverty lines in 2011 PPPs. Those estimates relied on CPIs from WDI, rather than CPIs from PovcalNet to convert the national poverty lines from their 2005 value to the 2011 value. The estimate of a 1.70 line matched the value of one of the lines prepared by Shaohua Chen for a background paper to Jolliffe et al. (2014).

${ }^{19}$ If we re-rank the countries by mean consumption denominated in 2011 PPPs, one country in the bottom 15 changes - and the mean of the lines in 2011 PPPs becomes \$1.79. In principle, one could also assert that an alternative, consistent approach to re-estimating the value of the line would be to re-estimate the relationship between national poverty lines and national income and consequently select a new sample of the poorest countries. That is to say the new line would not necessarily be based on the same 15 countries that produced the $\$ 1.25$ line.
} 


\section{B. Reconsidering the Global Poverty Line - An Alternative, Robust Approach}

For the last 25 years, the underlying concept of the global poverty line has been that it should reflect some average or typical value of national poverty lines for the poorest of countries (World Bank, 1990; Ravallion, van de Walle and Datt, 1991). The last time the line was estimated, Ravallion, Chen, Sangraula (2009) estimated the line based on selecting the 15 poorest countries from a sample of 75 countries for which they had national poverty lines of any type. While a sample of 75 poverty lines was much larger than what had been used to estimate the dollar-a-day line at 1993 PPPs, it is noteworthy that it is a select sample of countries for which the authors could collect national poverty lines. The authors note for example that Latin America was a region with poor coverage in their sample.

Deaton (2010) critiques this 15-country approach for several reasons, most of which link to the fundamental problem that these countries provide weak support for representing the world's poor. As one example, he describes how small changes in the composition of the 15-country reference group can result in changing the poverty status of millions of people. He further notes that the decision to select countries into the 15-country reference group is based on mean per capita income of the country and not the number of poor people. The 15 countries represent about 11 percent of the total poor in 2005, and about 13 percent of the estimated poor in 2011.

In addition to the weak support, the average poverty line estimated from these 15 countries is quite sensitive to seemingly innocuous changes in the time series of inflation data for these countries. The sensitivity of the average to changes in inflation data stems both from the small sample of 15 and also from the fact that the poverty lines from these countries need to be updated from the year of data collection to the reference year (2011 in our case). Table 2 reveals that on average, the 15 reference national poverty lines date from 1997. The poverty line from Mali 
comes from 1988-89 and requires 22 years of CPI data to bring it to the 2011 reference period. Given that many of these 15 countries have limited capacity for statistical production and some have experienced very high levels of inflation, a reasonable concern is that even small errors or relatively minor updates when compounded over decades can have potentially large effects on the estimated value of the global poverty line. ${ }^{20}$

As one example of the sensitivity of the average poverty line to inflation data, in our initial analysis we updated the 15 poverty lines to 2011 values based on official national CPI data as reported in the World Development Indicators database. This updating produced a global poverty line of \$1.70 using 2011 PPPs and about 976 million poor people. In the current analysis, we use the inflation data provided by PovcalNet (to ensure internal consistency) and this changed the average value of the poverty lines to $\$ 1.82$ and increased the count of the poor by more than 60 million people. Overall, the majority of the inflation data in PovcalNet comes from the World Development Indicators database, and even in those cases where they differ, the differences are not large, but nonetheless the 15-country reference approach is highly sensitive to these differences.

To address these concerns, we propose a methodology for constructing a global poverty line that is less sensitive to inflation updating, more robust to the small-sample problems stemming from the 15-country approach, and also significantly increases the coverage of the population of poor people. Our proposed approach is based on estimating implicit national poverty lines by combining poverty headcounts at national poverty lines as reported in the World

\footnotetext{
${ }^{20}$ Sandefur (2013) shows that there is a large discrepancy between official estimates of inflation in Tanzania (one of the 15 reference countries) and household survey-based estimates of price changes. He also illustrates how these differences in inflation estimates have significant effects on the trend in poverty headcounts. Gimenez and Jolliffe (2014) document significant discrepancies between official measures of inflation in Bangladesh, survey-based measures of inflation for the poor, and implicit measures of inflation as assessed through official poverty lines.
} 
Development Indicators with the corresponding consumption and income distributions from PovcalNet. ${ }^{21}$ Because the consumption and income distributions we use are all expressed in per capita PPP terms, we can identify the unique poverty line in PPP dollars that corresponds with the reported headcount for the national poverty line. ${ }^{22}$ Following this approach allows us to greatly increase the set of countries for which we have national poverty thresholds (thereby increasing the support of our estimate) and also produces a series of poverty lines that are closer to the ICP reference year (thereby reducing the sensitivity of the estimate to errors and updates in inflation data).

More specifically, we extract poverty headcounts from the World Bank’s series of poverty headcount ratios at national poverty lines in its Poverty and Inequality Database. ${ }^{23}$ This data set contains 784 poverty rates at national poverty lines. Of these, 623 observations from 110 countries can be matched to surveys available in PovcalNet. Using this, we derive 623 thresholds which reflect the national poverty rate when applied to the PovcalNet per capita welfare measure - more than an eightfold increase over the number of poverty lines used by Ravallion, Chen, and Sangraula. $^{24}$

\footnotetext{
${ }^{21}$ For the purposes of our analysis, we use the same fitted distributions as used in the other parts of this paper. In principle, one could use the actual consumption data for those countries where we have this. See the annex for more details on how we generate our fitted consumption and income distributions.

${ }^{22}$ An attribute of this approach is that it allows us to identify the national average poverty line even in those countries where no national line exists, but only regional lines or lines for household types.

${ }^{23}$ The series is called Poverty headcount ratio at national poverty lines (\% of population), including noncomparable values (SI.POV.NAHC.NC). National poverty headcount ratio is the percentage of the population living below the national poverty lines. National estimates are based on population-weighted subgroup estimates from household surveys. The source for this data is the World Bank's Global Poverty Working Group. Data are compiled from official government sources or are computed by World Bank staff using national (i.e. country-specific) poverty lines. The database is available at http://databank.worldbank.org/data/views/variableselection/selectvariables.aspx?source=Poverty-andInequality-Database.

${ }^{24}$ In addition to having much greater coverage of the population of poor people, and having more recent lines; we believe this approach produces a set of lines that are more comparable across countries than those used in Chen, Ravallion and Sangraula (2009).
} 
Plotting these national poverty lines on the log of per capita consumption reveals a positive gradient over the entire range of mean consumption, suggesting that national poverty lines are increasing in consumption for even the poorest of countries. ${ }^{25}$ We are therefore not able to replicate the methods used by Ravallion, Chen and Sangraula to identify the threshold below which national poverty lines do not increase with mean consumption and use this as a reference group for the international poverty line. Given that we have no data-driven basis on which to select national poverty lines from our sample of 623 lines, we propose to form an international poverty line reflective of national poverty thresholds among countries classified as "low-income" by the World Bank. While the World Bank's income classification is admittedly arbitrary, it is nonetheless well established and has stayed constant over time. ${ }^{26}$

Panel A of Figure 2 plots all of our 623 estimates of national poverty lines in 2011 PPP dollars and highlights the poverty lines used in years when the country was classified as a LowIncome Country (LIC) by the World Bank. Panel B focuses in on the 155 observations for LICs and highlights the latest observation for existing LICs. Because of the limitations of relying on CPI over long time periods, we restrict the sample to only allow one observation per country and select the most recent observation if there are multiple estimates of national lines. This gives a set of 32 national poverty thresholds for LICs, with a median value of $\$ 1.92$. These 32 countries more than double the coverage of the poor relative to the 15-country approach. In 2005, the sample of 32 countries represent about 25 percent of the population of poor people.

\footnotetext{
${ }^{25}$ This finding is in contrast to Ravallion, Chen and Sangraula (2009) who find that for the poorest of countries, national poverty lines are not increasing in consumption.

${ }^{26}$ As of 1 July 2014, low-income economies are defined as those with a GNI per capita, calculated using the World Bank Atlas method, of \$1,045 or less in 2013; middle-income economies are those with a GNI per capita of more than $\$ 1,045$ but less than $\$ 12,746$; high-income economies are those with a GNI per capita of $\$ 12,746$ or more. Lower-middle-income and upper-middle-income economies are separated at a GNI per capita of $\$ 4,125$.
} 
As another attribute, the 32 thresholds are on average from 2008 and thus much less sensitive to errors in national CPI, than the ones underpinning the $\$ 1.25$ line which on average are from 1997. We take median values of the lines, rather than means, to reduce the potential issue that over time we expect there to be more bunching at the upper portion of the low-income cutoff. ${ }^{27}$ Repeating this exercise to estimate a LIC line using 2005 PPP data, the median value of the poverty lines is $\$ 1.25 .^{28}$ The fact that this procedure results in an estimated poverty line that exactly coincides with the widely accepted $\$ 1.25$ global poverty line is a desirable attribute in terms of avoiding revisions to global poverty headcounts denominated in 2005 PPPs.

\section{Poverty Goals and Profiles with 2011 PPP}

The rest of the analysis is based on exploring the current, past, and future profiles of our candidate global poverty lines in 2011 PPPs (\$1.82 and \$1.92) and compares them each with the 2005 \$1.25 line.

\section{A. Global Profiles of Poverty in 2011}

The latest World Bank (2014a) poverty estimates for 2011 suggest that 1.01 billion people, or 14.5 percent of the global population, live below the \$1.25 line in 2005 PPPs. As discussed in the previous section, these estimates are using adjusted 2005 PPPs for China, India, and Indonesia to

\footnotetext{
${ }^{27}$ Of the 623 poverty lines, 155 come from countries that were classified as low-income countries and as such form our reference sample for the global poverty line. A country can be observed multiple times in this reference sample if they have multiple poverty headcount estimates across years. And, since the real value of national poverty lines frequently change, we argue that multiple entries for a country should be included in our estimates. To prevent a country from having greater influence on the average simply because it has poverty lines for several years, we weight each line by the reciprocal of the number of times it appears in the sample. For example, if a country has three poverty lines in the reference sample, then each line receives a weight of one third. The resulting weighted median value of these 155 poverty lines is \$2.05 (based on inflating each line to the reference year of 2011, and using the 2011 PPP exchange rates). We also are exploring alternative taking the midpoint value from a fitted line, where the midpoint is defined over the GNI range of low-income countries.

${ }^{28}$ This estimate is $\$ 1.26$ when we expand our sample to consider all observations of poverty line for each Low Income Country ( $\mathrm{n}=155)$.
} 
correct for presumed sampling bias in the 2005 ICP and rural-urban price differences in the country. For the analysis in this paper, we estimate fitted distributions of consumption and income for every country and then derive poverty estimates from these distributions. Because we are using fitted Lorenz curves, the estimates reported in this paper differ slightly from World Bank (2014a) but the differences are small. For example, in our replication of the global count based on the \$1.25 line and the 2005 PPPs, we get the same estimate of 1.01 billion poor in 2011, and a global poverty rate of 14.5 percent, which is the same as the World Bank's official 14.5 percent. ${ }^{29}$ Our regional profile is nearly identical with Jolliffe et al. (2014) as well as the country-by-country comparisons. ${ }^{30}$ Despite slight differences with Jolliffe et al. (2014), an important advantage of our approach is that the analysis is based on readily available, public data which improves transparency, and the use of fitted distributions allows us to project forward (and back) in time the entire distribution.

Using the 2011 PPP data with the urban-rural adjustments removed from China, India and Indonesia, along with the re-estimated $\$ 1.82$ poverty line, we estimate a global poverty rate of 14.9 percent in 2011. This is 0.4 percentage point greater than the World Bank (2014a) estimate for 2011 based on the $\$ 1.25$ line using 2005 PPPs. Using the \$1.92 line gives us a poverty rate of 16.7 percent in 2011. These estimates differ markedly from public perception, largely informed by Chandy and Kharas and Dykstra, Kenny and Sandefur, primarily because of the removal of the 2005 urban-bias adjustments in the 2011 PPP analysis. When we maintain the poverty line at $\$ 1.82$ but use the adjusted 2011 PPP data, the estimated poverty rate falls to 11.1 percent. This is

\footnotetext{
${ }^{29}$ Similar to Jolliffe et al. (2014), we assume both that the world population in 2011 is 6.96 billion and that there is no extreme poverty in rich countries (using the same classification as in in Jolliffe et al. (2014)). Throughout this paper we use the same aggregation and 'line-up' method as PovcalNet and explained in Jolliffe et al. (2014).

30 The only region where the estimate from our data differs slightly from the PovcalNet estimates is in the Latin America region. For more details on the data used for our estimation and how it differs from PovcalNet estimates, see Annex 1.
} 
equivalent to 300 million people being re-classified as not poor, similar in magnitude to the analysis of Chandy and Kharas. Similarly, if we use the \$1.44 line used by Dykstra, Kenny and Sandefur, the adjusted 2011 PPP analysis results in a decline by more than a half as compared to the face-value 2011 PPP analysis, a decline that is similar in magnitude to that found by Dykstra, Kenny and Sandefur.

The analysis based on the 2011 PPP data and the \$1.82 line presents a global count of poor people that is very similar to the global count based on the \$1.25 line and the 2005 PPPs. However, some of the regional changes are larger. For example, in the East Asia and the Pacific region, poverty increases from 8.0 percent under the $\$ 1.25$ line to 13.2 percent under the $\$ 1.82$ line. This increase is largely driven by an upward adjustment to the poverty headcount in China. Under both the 2005 and 2011 PPPs, the largest number of poor people in 2011 is in SubSaharan Africa, followed by the South Asia region. However, the number of poor people living in poverty is somewhat lower in these two regions under the $\$ 1.82$ line (by about 10 and 50 million in each of these regions, respectively). The Middle East and North Africa region experienced some of the largest revisions to the PPP data between the 2005 and 2011 ICP rounds, but because of the very low poverty rates at the extreme poverty lines in both 2005 and 2011 PPPs, this matters little for our global results. However, at higher poverty lines, the changes to poverty estimates for this region are much more substantial. ${ }^{31}$ While the regional realignment of

\footnotetext{
${ }^{31}$ For example, for a $\$ 3$ dollar a day poverty line in 2011 PPPs, we estimate a global poverty rate of $32.4 \%$ in 2011, similar to the 30.9\% for the closely corresponding 2 dollar a day poverty line in 2005 PPPs. However, for the Middle East and North Africa, the corresponding estimates change much more, from $11.4 \%$ to $5.4 \%$.
} 
the profile is significant, it is nonetheless substantially less jarring than with the adjustments made after the release of the 2005 PPP data.

In addition to examining the differences in the regional profile of poverty, it is also useful to compare country-specific poverty rates based on the 2005 PPP (and \$1.25 line) with the 2011 PPP (and the \$1.82 line). This is not an argument to suggest that the estimates should be assessed on how close they match the existing estimates based on the 2005 PPP data, but rather an exercise to understand how much the profile of poverty would change if the \$1.82 line were adopted with the 2011 PPP conversion factors. A bivariate regression between the two rates, where each country is an observation, gives a slope coefficient of 1.00 and an R-squared of 0.95. Similarly, the rank correlation gives a Spearman's rho coefficient of 0.97 . The basic bivariate analysis suggests very strong country-by-country correspondence, and Figure 3 illustrates that the change in poverty rates and ranking of countries is reasonably small without many outliers. For 75 percent of the countries, the poverty headcount changes by five percentage points or less when changing from the $\$ 1.25$ line at 2005 PPPs to the $\$ 1.82$ at 2011 PPPs. For 10 percent of the countries, this change is greater than 8.5 percentage points.

Figure 3 provides a portrayal of the difference for each country between the estimated poverty rate in 2011 based on the \$1.25 line (and 2005 PPPs) and the \$1.82 line (and 2011 PPPs). In addition to asserting a strong bi-variate correlation between these two estimates, an alternative way of assessing the difference is to take the mean value of absolute deviations for each country. Figure 4 carries out this exercise for all poverty lines ranging from 1 to 3 dollars per day (estimated at intervals of 10 cents). More specifically, Figure 4 depicts the mean absolute difference in (percentage points) poverty rates at the country level between the \$1.25 line in 2005 PPPs and poverty rates at various poverty lines in 2011 PPPs. The mean absolute difference in 
country-level poverty rates is minimized with a poverty line at around $\$ 1.85$ per day. This illustrates that the $\$ 1.82$ and $\$ 1.92$ lines are close to the poverty line which minimizes the changes to poverty rates at the country level.

Looking more closely at the 10 countries with the highest poverty headcount in 2011 (as assessed with the $\$ 1.25$ poverty line and the 2005 PPPs), Figure 5 shows how these counts change when moving from the 2005 PPP with the \$1.25 line to the 2011 PPP with the \$1.82 line. These 10 countries represent 73 percent of the world's poor in 2011. China stands out with a large increase in the number of extreme poor compared to other countries and regions. Using the \$1.82 line at 2011 PPPs, the poverty headcount more than doubles from 85.2 million to 200 million. In contrast, Pakistan and Bangladesh show relatively large declines, about halving our assessment of poverty in these two countries. Other changes are relatively more modest. In terms of country rankings, overall 50 percent of countries experience a global absolute re-ranking of less than four places, and 85 percent shift less than 10 ranks.

The changes to poverty estimates at the country level and relative rankings between countries caused by going from the $\$ 1.25$ poverty line and 2005 PPPs to $\$ 1.82$ (or $\$ 1.92$ ) and 2011 PPPs are much smaller than the changes caused by the introduction of the 2005 PPPs in 2008. Figure 6 replicates Figure 3 by comparing country level poverty rates and rankings under two different global poverty lines. Figure 6 depicts this change by comparing the $\$ 1.08$ poverty line and the 1993 PPPs (used until 2007), with the estimate using the \$1.25 line and the 2005 PPPs (introduced in 2008). When comparing these changes to those displayed in Figure 3, it is clear that the revision of global poverty measurement using the 2011 PPPs proposed by this paper causes significantly smaller changes than the revision associated with introducing the 2005 PPPs. The large "shake-up” of country level estimates and relative rankings is also reflected in 
bivariate estimates. The regression between poverty estimates resulting from the 1993 PPPs and 2005 PPPs, gives a slope coefficient of 1.06 and an R-squared of 0.65 . The Spearman's rho coefficient for a rank correlation for poverty measures in 1993 PPPs and 2005 PPPs is only 0.65.

\section{B. Poverty Projections and Past Trajectories}

How would using the 2011 PPPs at face value along with the $\$ 1.82$ poverty line affect our view of the evolution of poverty in recent decades? And, would the prospects for reaching the goal of ending extreme poverty in 2030 change? Projections of global poverty so far into the future are very uncertain, regardless of the poverty line or PPPs used. Nevertheless, for the purpose of comparison with existing forecasts, we replicate the methodology used for the most recent projections of global poverty in Jolliffe et al. (2014). We conduct simulations for two separate growth scenarios - the first is based on each country's average 10-year historic growth, which may represent an optimistic scenario; and the second is based on average growth rates over the last 20 years, which are lower on average. ${ }^{32}$ The projection method assumes distribution neutral growth, holding inequality unchanged within each country and that populations grow in line with projections available in the WDI.

The results of the projections are shown in Figure 7 and suggest that global poverty measured and projected using the \$1.82 and \$1.92 lines at 2011 PPPs follow a very similar trajectory to the one for the $\$ 1.25$ line at 2005 PPPs from 1981 until 2030. Figure 8 details the projections to 2030 under alternate growth scenarios. For the \$1.25 line and 2005 PPPs, we estimate that the poverty rate would decline from 14.5 percent in 2011 to 4.7 percent by 2030

\footnotetext{
${ }^{32}$ The growth rates used in the projections are the same as used in Jolliffe et al. (2014) and Lakner, Negre and Prydz (2014), which are based on annualized real growth rates of GDP per capita (countries in SubSaharan Africa) or national accounts 1 household final consumption per capita (all other countries). These growth rates are adjusted by a factor based on observed differences between national accounts growth and survey growth found by Ravallion (2003). A factor of 0.87 is used for all countries except China (0.72) and India (0.57). The 10 year growth rates are based on observations between 2001 and 2011, while the 20 year growth rates are based on 1990 to 2010.
} 
under the 10-year historic growth scenario. ${ }^{33}$ Our projection based on the $\$ 1.82$ line suggests a trajectory of global poverty declining from 14.9 percent in 2011 to 4.3 percent in 2030 . The $\$ 1.82$ line results in a global poverty estimate that is 0.4 percentage points higher than the World Bank (2014a) estimate of poverty in 2011, and 0.4 percentage points lower than the corresponding poverty estimate for 2030.

When considering the less optimistic growth scenario based on the 20-year average growth rate, the $\$ 1.82$ line results in a global poverty estimate for 2030 that is a percentage point less than the projection to 2030 based on the $\$ 1.25$ line. The poverty estimate starts out 0.4 percentage points higher than the World Bank (2014a) estimate for 2011, but by 2030, the global poverty estimate based on the $\$ 1.82$ line is 5.8 percent. The 2030 projection based on the $\$ 1.25$ line and 20-year average growth rate is 6.8 percent. In short, even though the \$1.82 line results in poverty estimates that are greater than those estimated by the $\$ 1.25$ line, this ranking is reversed under both growth projections. The more rapid decline in global poverty seen under the 2011 PPPs is mainly because the global poverty profile in 2011 PPPs has a higher concentration of poverty in countries which are expected to grow relatively faster until 2030 than the profile based on the 2005 PPPs, assuming the 10 and 20 year historic growth rates.

Table 3 compares the projected regional profile of poverty at the \$1.25 line (2005 PPPs) with the profiles based on the $\$ 1.82$ and $\$ 1.92$ lines (2011 PPPs) for three points in time: 1990, 2011, and 2030. The projections for 2030 are based on the country-specific 10-year historic average growth rates. Notably, projections for 2030 for all three lines suggest that there will be close to 400 million poor people in 2030 - the vast majority of whom will be in Sub-Saharan Africa (more than 85 percent across all three cases considered). For example, assuming country-

${ }^{33}$ This is very similar to the trajectory from 14.5 to 4.8 estimated by Jolliffe et al. (2014). 
average growth based on the 10-year history, the $\$ 1.82$ line estimates that 362 million people will be poor, of whom, 317 million (or 88 percent) will be in Sub-Saharan Africa.

Looking back at the estimates for the period 1981-2011, the trajectory for global poverty is largely similar for the \$1.82 line at 2011 PPPs and \$1.25 at 2005 PPPs. As with the estimates for 2011, the regional estimates for 1990 show a higher concentration of poverty in East Asia and the Pacific for the $\$ 1.82$-line than the $\$ 1.25$ line (Table 3). It is particularly noteworthy that the key indicator for the first Millennium Development Goal, halving the global poverty rate from its 1990 level, is estimated to have been reached between 2008 and 2010 under both the \$1.25 and \$1.82 lines and respective PPPs.

Figure 9 summarizes estimated poverty rates in 2011 and 2030 for a range of possible poverty lines in 2011 PPPs (ranging from 1 to 3 dollars per day), in effect tracing the global cumulative distribution functions for this segment of the global income distribution. The \$1.82 and \$1.92 lines are in the range where the global poverty rate in 2011 changes fairly significantly with small changes in the poverty line, as can be seen by the relative steepness of the 2011 line for global poverty estimates over all lines. Moving the poverty line by 10 cents (from $\$ 1.82$ to \$1.92), increases the poverty rate from 14.9 percent to 16.7 percent - or approximately 120 million people. In contrast, the change in 2030 poverty estimates from increasing the poverty line from $\$ 1.82$ to $\$ 1.92$ is relatively small, as illustrated by the relatively flat gradient of poverty estimates for both growth scenarios in this range. Estimates for any poverty line above approximately $\$ 1.60$ will fall short of the World Bank’s 3 percent goal under both the 10 and 20 year growth scenarios. 


\section{Discussion}

An immediate response to some of the initial analysis of the 2011 PPP was that the change in the global poverty profile was in some way a statistical trick. The conversation was about how hundreds of millions of people became nonpoor overnight. This discussion led some to the view that global poverty estimates should be held constant with the adoption of the new 2011 PPP data. As one example, Kakwani and Son (2014) take quite literally the question of whether new PPP data should affect our estimates of poverty and answer with a resounding no.

In their approach, they develop a set of “equivalent poverty lines” in 2011 PPP terms for each country, which corresponds to the poverty line in 2005 PPPs. One way to view this approach is to say that they take the poverty headcount for 2010 as estimated by extrapolations of the 2005 PPP index as truth. They then back out the value of the poverty line in 2011 PPP terms that maintains the same headcount for each country. They are implicitly taking the view that we learn nothing about the true poverty status of individuals from the 2011 PPP data - if someone is identified as being poor based on extrapolating the 2005 PPP data out to 2011, then they should be identified as poor based on the 2011 PPP data.

The appeal of their approach is that it essentially washes away any communication concerns - poverty headcounts are kept exactly the same. International organizations can present themselves as not manipulating the poverty headcount, while also superficially presenting themselves as adopting the 2011 PPP data. But, following this approach leads one to an interesting position - the poverty line continues to either be measured in terms of 2005 PPP dollars or if measured in 2011 PPP dollars, no longer reflects the same standard of living across countries. 
Another proposal for adopting the 2011 PPPs has been the so-called "continuous headcount approach.” This approach sets the poverty line at whatever value is needed to maintain the global headcount ratio at 14.5 percent in 2011 when using the 2011 PPP conversion factors. Underlying this method, there is no interest in ensuring that the new global poverty line reflects the same standard of living in the world's poorest countries in 2011 as in 2005. The fundamental interest is in ensuring that the new PPP data on price levels do not affect the global count of poor. It is important to recognize though, that the number of poor is only kept constant at the global level - the poverty headcounts would change in most every country.

While it might be attractive to communicate that the global poverty rate is unchanged, fixing the poverty rate at 14.5 percent in 2011 is essentially a statement asserting that we place more faith in the global level of poverty as estimated by 2005 PPP data that has been extrapolated out to 2011 as opposed to the poverty level implied by the new 2011 PPP data. Yet, at the same time, such an approach would imply that for comparison between countries, the 2011 PPPs are most appropriate. This approach would also have the awkward property that any update or correction to the data that affected the estimated poverty level for a single country would force a revision to the global poverty line, and this revision would then lead to a change in poverty lines in all countries of the world.

This paper proposes answers to the questions of whether new PPP data should affect global poverty estimates, and if so, how. Our view differs from the view that poverty estimates should not change with the new PPP data. Extrapolations of old PPP data should provide reasonable approximations to new PPP data, but as with most all data collection efforts, there are always so-called seam issues when new data are introduced to a time series of statistics. There are likely flaws in the 2011 PPP data, but this will always be the case for efforts to collect price 
data across the world where product variation is significant. Our analysis essentially assumes that the signal in the 2011 PPP data provides a better portrayal of relative price levels across countries as compared to using the 2005 PPP data (combined with local inflation rates). And this assumption leads us to the view that current global poverty estimates should be based on the most recent price data.

In our analysis, we show that a consistent approach to global poverty estimation that includes incorporating the 2011 PPP data leads to poverty estimates that are close, but slightly higher, than those based on 2005 PPP extrapolations. The analysis in this paper suggests that if one accepts that the 2011 ICP have reduced the urban bias believed to exist in the 2005 PPP data, then the estimates suggest a relatively smooth transition between the two indices for global poverty estimation. Following the approach considered in this paper of using the 2011 PPP data at face value and a poverty line of $\$ 1.82$, the global headcount increases by 0.4 percentage point (or less than 3 percent) and the changes in the regional profile of poverty are substantially less than the changes introduced with the 2005 PPP data.

In addition to having a relatively small impact on global poverty estimates for 2011, using the 2011 PPP data (either at face value or with the 2005 urban-bias adjustments) has a similarly small effect on poverty projections for 2030. Analysis based on assuming that countries grow at a rate equal to country-specific average growth rates from the last 20 years projects a poverty rate of 6.6 percent when using the 2005 PPP data. Our analysis based on the face value 2011 PPP index and the $\$ 1.82$ line projects a poverty rate of 5.5 percent in 2030, well short of 'ending' extreme poverty. Our analysis also reveals that poverty projections to 2030 look very similar whether based on the adjusted or face value 2011 PPP index. Based on the more optimistic 10year average growth rates, poverty is projected to be 4.3 percent based on the $\$ 1.82$ line and the 
2011 PPPs (used at face-value). ${ }^{34}$ When considering the same growth scenario, but using the \$1.25 line and the 2005 PPPs, poverty is projected to be 4.7 percent. Similarly, when considering the higher \$1.92 line based on the LIC country status and the 2011 PPPs, poverty is projected to be 4.8 percent. An important implication of these projections is that the poverty estimates for 2030 based on the 2011 PPP conversion factors and either the $\$ 1.82$ or $\$ 1.92$ lines are very similar to the projections reported in Jolliffe et al. (2014) based on the \$1.25 line at 2005 PPPs. They are all within half a percentage point of each other and suggest that the global poverty goals assessed using 2011 PPPs are not significantly more or less attainable than they were when they were announced in 2013.

\footnotetext{
${ }^{34}$ Despite there being a very large difference in poverty rates for 2011 between using PPPs at face value or with the adjustments, by 2030 this differences essentially disappears. The 2030 poverty projection based on the adjusted PPPs is 4.2 percent.
} 


\section{References}

Abdelkrim, A. and J.-Y. Duclos. (2007) “DASP: Distributive Analysis Stata Package.” PEP, World Bank, UNDP and Université Laval.

Chandy, L. and Kharas, H. (2014) “The Poverty of Poverty Data.” Brookings Institution blog, http://www.brookings.edu/blogs/up-front/posts/2014/10/10-global-poverty-data-chandykharas.

Chen, S., \& Ravallion, M. (2008). “China is poorer than we thought, but no less successful in the fight against poverty”. World Bank Policy Research Working Paper, (4621).

Chen, S. and Ravallion, M. (2010) “The Developing World is Poorer than we Thought, But no Less Successful in the Fight against Poverty.” Quarterly Journal of Economics, 125(4), 1577-1625.

Deaton, A. (2010). “Price Indexes, Inequality, and the Measurement of World Poverty.” American Economic Review, 100(1): 5-34.

Deaton, A. (2005) “Measuring Poverty in a Growing World (or Measuring Growth in a Poor World).” Review of Economics and Statistics, 87(1):1-19.

Deaton, A. and Aten, B. (2014) “Trying to Understand the PPPs in ICP2011: Why are the Results so Different?” NBER Working Paper No 20244, June, 2014.

Dykstra, S., Kenny, C. and Sandefur, J. (2014) “Global Absolute Poverty Fell by Almost Half on Tuesday.” Centre for Global Development blog: http://www.cgdev.org/blog/globalabsolute-poverty-fell-almost-half-tuesday.

Gimenez, L. and Jolliffe, D. (2014) "Inflation for the Poor in Bangladesh: A Comparison of CPI and Household Survey Data.” Bangladesh Development Studies, 37(1/2): 57-81. 
Inklaar, R. and Rao, D. S. (2014) “Cross-country income levels over time: did the developing world suddenly become much richer?” GGDC Research Memorandum Working Paper no. 151. http://www.ggdc.net/publications/memorandum/gd151.pdf

Jolliffe, D., Lanjouw, P., Chen, S., Kraay, A., Meyer, C., Negre, M., Prydz, E., Vakis, R. and Wethli, K. (2014) A Measured Approach to Ending Poverty and Boosting Shared Prosperity: Concepts, Data, and the Twin Goals. Policy Research Report. Washington, DC: World Bank, doi:10.1596/978-1-4648-0361-1.

Kakwani, N., and Son, H. (2014) “Global Poverty Estimates Based on 2011 Purchasing Power Parity: Where Should the New Poverty Line be Drawn?” mimeo.

Lakner, C., and Milanovic, B. (2014) Global income distribution: From the fall of the Berlin Wall to the Great Recession. World Bank Policy Research Working Paper. (Updated forthcoming version).

Lakner, C., Negre, M., and Prydz, E. B. (2014) “Twinning the goals: how can promoting shared prosperity help to reduce global poverty?” World Bank Policy Research Working Paper, (7106).

Ravallion, M. (2014) “An Exploration of the International Comparison Program’s New Global Economic Landscape.” NBER Working Paper No 20338, July, 2014.

Ravallion, M., Shaohua C. and Sangraula, P. (2009) "Dollar a day revisited." The World Bank Economic Review, 23(2): 163 - 184. doi: 10.1093/wber/lhp007

Ravallion, M., Datt, G., \& Walle, D. (1991) “Quantifying absolute poverty in the developing world.” Review of Income and Wealth, 37(4), 345-361. 
Sandefur, J. (2013). “Africa Rising? Using Micro Surveys to Correct Macro Time Series.” Center for Global Development, mimeo, https://editorialexpress.com/cgi-bin/conference/ download.cgi?db_name=NEUDC2013\&paper_id=457.

Shorrocks, A. and Wan, G. (2008). "Ungrouping Income Distributions: Synthesising Samples for Inequality and Poverty Analysis.” WIDER Research Paper series no. 2008/16. United Nations University, Helsinki. www.wider.unu.edu/ publications/workingpapers/research-papers/2008/en_GB/rp2008-16/

World Bank. (2013) “Historic Goals to End Extreme Poverty Endorsed by World Bank Governors,” Press Release no. 2013/356/EXT, Washington, DC: World Bank. http://www.worldbank.org/en/news/press-release/2013/04/20/historic-goals-to-endextreme-poverty-endorsed-by-world-bank-governors

World Bank. (2014a) Global Monitoring Report 2014/2015: Ending Poverty and Sharing Prosperity. Washington, DC: World Bank. doi: 10.1596/978-1-4648-0336-9.

World Bank. (2014b). International Comparison Program: Detailed data and metadata for researchers. Washington, DC: World Bank.

World Bank. (2015). Purchasing Power Parities and the Real Size of World Economies: A Comprehensive Report of the 2011 International Comparison Program. The World Bank. doi: 10.1596/978-1-4648-0329-1. 
Tables

Table 1: Estimates of Percent Poor in 1993 based on 3 PPP Indices

\begin{tabular}{lccc}
\hline & $\begin{array}{c}\text { 1985 ICP- } \\
\text { PPP index }\end{array}$ & $\begin{array}{c}\text { 1993 ICP- } \\
\text { PPP index }\end{array}$ & $\begin{array}{c}\text { 2005 ICP- } \\
\text { PPP index }\end{array}$ \\
\hline Poverty line & $\$ 1.01$ & $\$ 1.08$ & $\$ 1.25$ \\
\hline East Asia and Pacific & 26.0 & 25.2 & 50.8 \\
Europe \& Central Asia & 3.5 & 3.5 & 4.3 \\
Latin America \& Caribbean & 23.5 & 15.3 & 10.1 \\
Middle East \& North Africa & 4.1 & 1.9 & 4.1 \\
South Asia & 43.1 & 42.4 & 46.9 \\
Sub-Saharan Africa & 39.1 & 49.7 & 56.9 \\
\hline Global Poverty Prevalence & 29.4 & 28.2 & 39.2 \\
Poverty Population (millions) & 1,350 & 1,304 & 1,799 \\
\hline
\end{tabular}

Source: Deaton (2010). 
Table 2: “15 poorest” National Poverty Lines at 2005 and 2011 PPPs

\begin{tabular}{|c|c|c|c|c|}
\hline \multirow[b]{2}{*}{ Country } & \multirow[b]{2}{*}{ Survey } & \multicolumn{2}{|c|}{ National poverty line } & \multirow{2}{*}{$\begin{array}{l}\text { CPI } 2011 \\
2005=100\end{array}$} \\
\hline & & 2005 PPPs & 2011 PPPs & \\
\hline Malawi & 2004-05 & 0.86 & 1.34 & 214.6 \\
\hline Mali & 1988-89 & 1.38 & 2.15 & 119.8 \\
\hline Ethiopia & $1999-2000$ & 1.35 & 2.03 & 297.1 \\
\hline Sierra Leone & 2003-04 & 1.69 & 2.73 & 203.9 \\
\hline Niger & 1993 & 1.10 & 1.49 & 116.3 \\
\hline Uganda & 1993-98 & 1.27 & 1.77 & 178.0 \\
\hline Gambia, The & 1998 & 1.48 & 1.82 & 129.3 \\
\hline Rwanda & 1999-2001 & 0.99 & 1.56 & 163.6 \\
\hline Guinea-Bissau & 1991 & 1.51 & 2.16 & 124.8 \\
\hline Tanzania & 2000-01 & 0.63 & 0.88 & 169.9 \\
\hline Tajikistan & 1999 & 1.93 & 3.18 & 334.2 \\
\hline Mozambique & 2002-03 & 0.97 & 1.26 & 173.5 \\
\hline Chad & 1995-96 & 0.87 & 1.27 & 111.1 \\
\hline Nepal & 2003-04 & 0.87 & 1.52 & 170.2 \\
\hline Ghana & 1998-99 & 1.83 & 2.13 & 205.4 \\
\hline Average & & 1.25 & 1.82 & \\
\hline
\end{tabular}

Source: National poverty lines in 2005 PPPs from Ravallion, Chen and Sangraula (2009). Poverty lines in 2011 PPPs are authors' estimates based on CPI data from PovcalNet

(http://iresearch.worldbank.org/PovcalNet/index.htm?0,3) and PPP data from ICP 2011. 
Table 3: Poverty by region, for 1990, 2011 and 2030

\begin{tabular}{|c|c|c|c|c|c|c|c|c|c|}
\hline \multirow[t]{4}{*}{ (a) Percent Poor } & \multicolumn{3}{|c|}{1990} & \multicolumn{3}{|c|}{2011} & \multicolumn{3}{|c|}{$2030^{*}$} \\
\hline & $\$ 1.25$ & $\$ 1.82$ & $\$ 1.92$ & $\$ 1.25$ & $\$ 1.82$ & $\$ 1.92$ & $\$ 1.25$ & $\$ 1.82$ & $\$ 1.92$ \\
\hline & 2005 & 2011 & 2011 & 2005 & 2011 & 2011 & 2005 & 2011 & 2011 \\
\hline & PPPs & PPPs & PPPs & PPPs & PPPs & PPPs & PPPs & PPPs & PPPs \\
\hline East Asia and Pacific & 56.9 & 66.4 & 68.0 & 8.0 & 13.2 & 14.8 & 0.3 & 0.3 & 0.4 \\
\hline Europe and Central Asia & 2.4 & 2.5 & 3.0 & 0.9 & 0.9 & 1.1 & 0.1 & 0.0 & 0.1 \\
\hline $\begin{array}{l}\text { Latin America and the } \\
\text { Caribbean }\end{array}$ & 12.9 & 15.6 & 16.8 & 5.1 & 5.8 & 6.3 & 2.6 & 3.0 & 3.4 \\
\hline $\begin{array}{l}\text { Middle East and North } \\
\text { Africa }\end{array}$ & 5.1 & 2.8 & 3.4 & 1.7 & 0.6 & 0.8 & 0.6 & 0.1 & 0.2 \\
\hline South Asia & 54.2 & 50.0 & 54.0 & 24.6 & 21.3 & 25.0 & 1.3 & 0.9 & 1.2 \\
\hline Sub-Saharan Africa & 56.6 & 54.7 & 57.2 & 46.9 & 44.2 & 46.8 & 23.7 & 22.4 & 24.2 \\
\hline Total & 35.9 & 37.8 & 39.6 & 14.5 & 14.9 & 16.7 & 4.7 & 4.3 & 4.8 \\
\hline \multirow[t]{4}{*}{ (b) Number of Poor } & \multicolumn{3}{|c|}{1990} & \multicolumn{3}{|c|}{2011} & \multicolumn{3}{|c|}{$2030 *$} \\
\hline & $\$ 1.25$ & $\$ 1.82$ & $\$ 1.92$ & $\$ 1.25$ & $\$ 1.82$ & $\$ 1.92$ & $\$ 1.25$ & $\$ 1.82$ & $\$ 1.92$ \\
\hline & 2005 & 2011 & 2011 & 2005 & 2011 & 2011 & 2005 & 2011 & 2011 \\
\hline & PPPs & PPPs & PPPs & PPPs & PPPs & PPPs & PPPs & PPPs & PPPs \\
\hline East Asia and Pacific & 911 & 1060 & 1090 & 157 & 261 & 293 & 7 & 6 & 8 \\
\hline Europe and Central Asia & 6 & 6 & 7 & 3 & 2 & 3 & 0 & 0 & 0 \\
\hline $\begin{array}{l}\text { Latin America and the } \\
\text { Caribbean }\end{array}$ & 54 & 66 & 71 & 29 & 33 & 37 & 18 & 21 & 23 \\
\hline $\begin{array}{l}\text { Middle East and North } \\
\text { Africa }\end{array}$ & 12 & 6 & 8 & 6 & 2 & 3 & 2 & 1 & 1 \\
\hline South Asia & 615 & 568 & 613 & 400 & 347 & 407 & 26 & 17 & 23 \\
\hline Sub-Saharan Africa & 287 & 277 & 290 & 416 & 392 & 416 & 336 & 317 & 344 \\
\hline Total & 1885 & 1984 & 2079 & 1010 & 1038 & 1158 & 389 & 362 & 399 \\
\hline
\end{tabular}

Note: Authors' estimates. *Projections based on 10 year historic growth rates. 


\section{Figures}

\section{Figure 1: Deriving international poverty lines from RCS 15 poorest national lines}
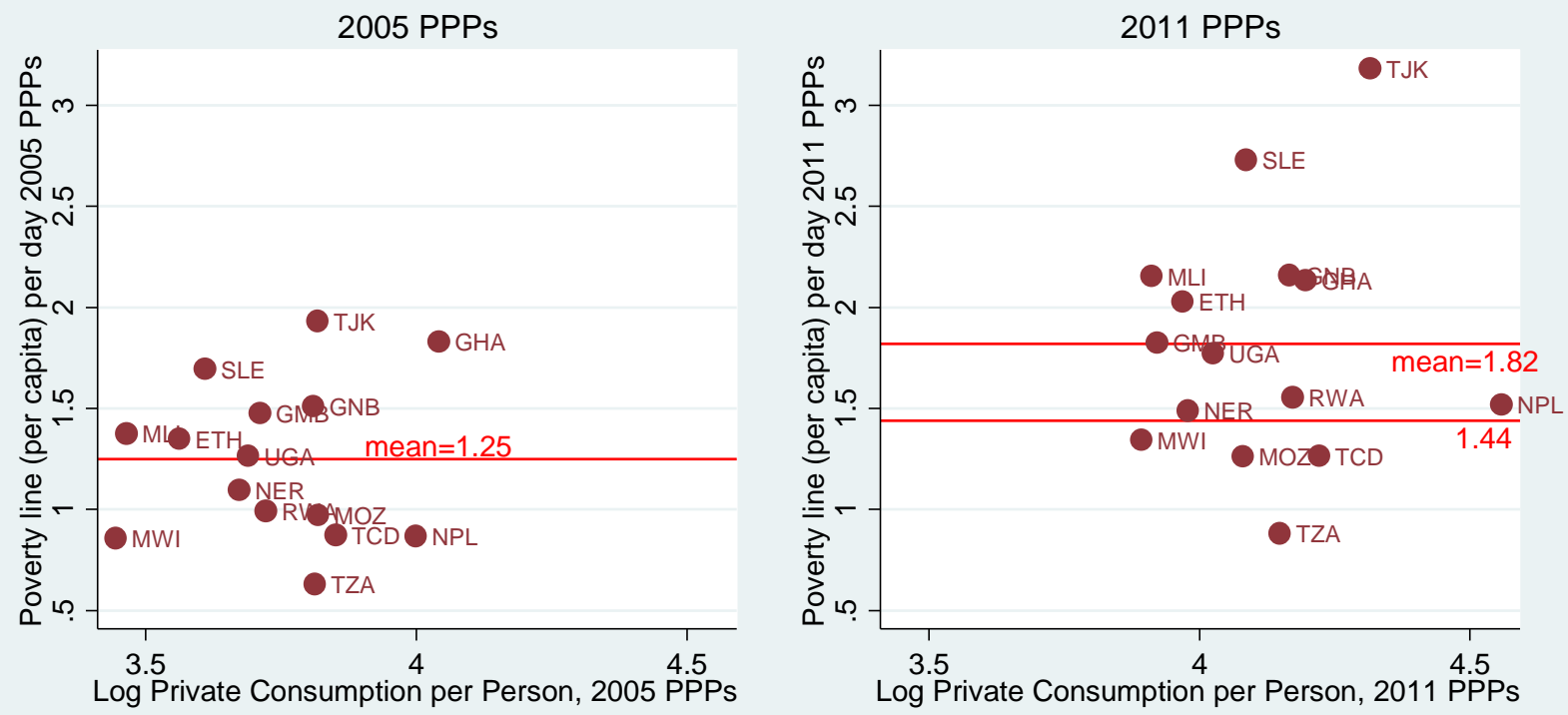

Note: The data in the left panel replicates the national poverty lines used in Ravallion, Chen and Sangraula (RCS, 2009) with focus on the 15 poorest countries used to derive the $\$ 1.25$ line. When 2005 PPPs are applied, the mean of the 15 national poverty lines is \$1.25. When 2011 PPPs are applied, the mean is \$1.82. Inflating the value of lines from 2005 to 2011 using inflation in the U.S. produces the $\$ 1.44$ line which would be at the low end of the poverty lines among this group of countries with only four of the 15 countries having lower lines in 2011 PPPs. 
Figure 2: National poverty thresholds by World Bank income classification
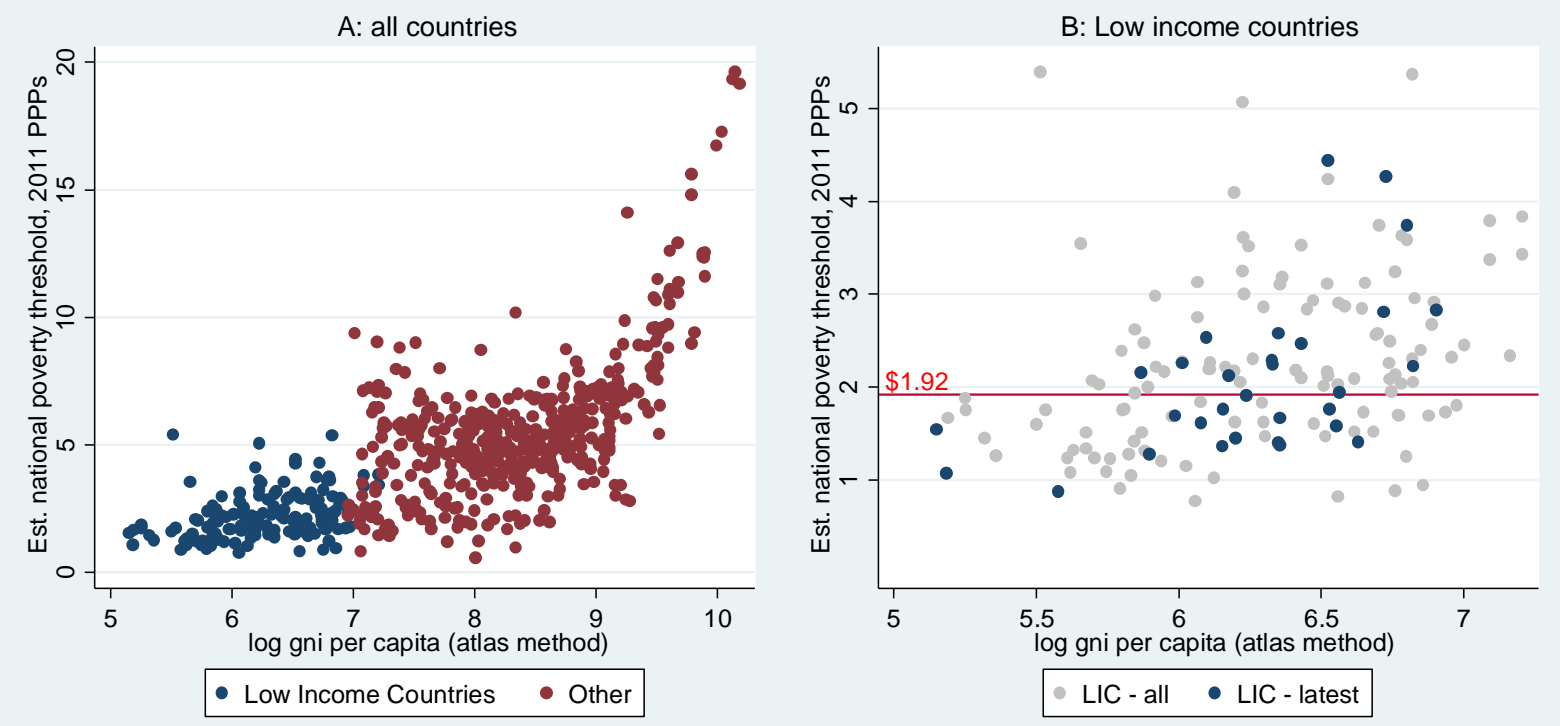

Note: The horizontal axis is denominated in gross national income (GNI) per capita following the Atlas method, which is the measure used for the World Bank's income classifications. Panel A shows the full sample, with the poverty lines parsed into whether the country was classified as low income status at the time of the survey. Panel B focuses in on the low income countries and shows the 32 latest observations and the estimated median of \$1.92. 
Figure 3: National poverty headcounts from 1.25 PPP05 vs 1.82 PPP11
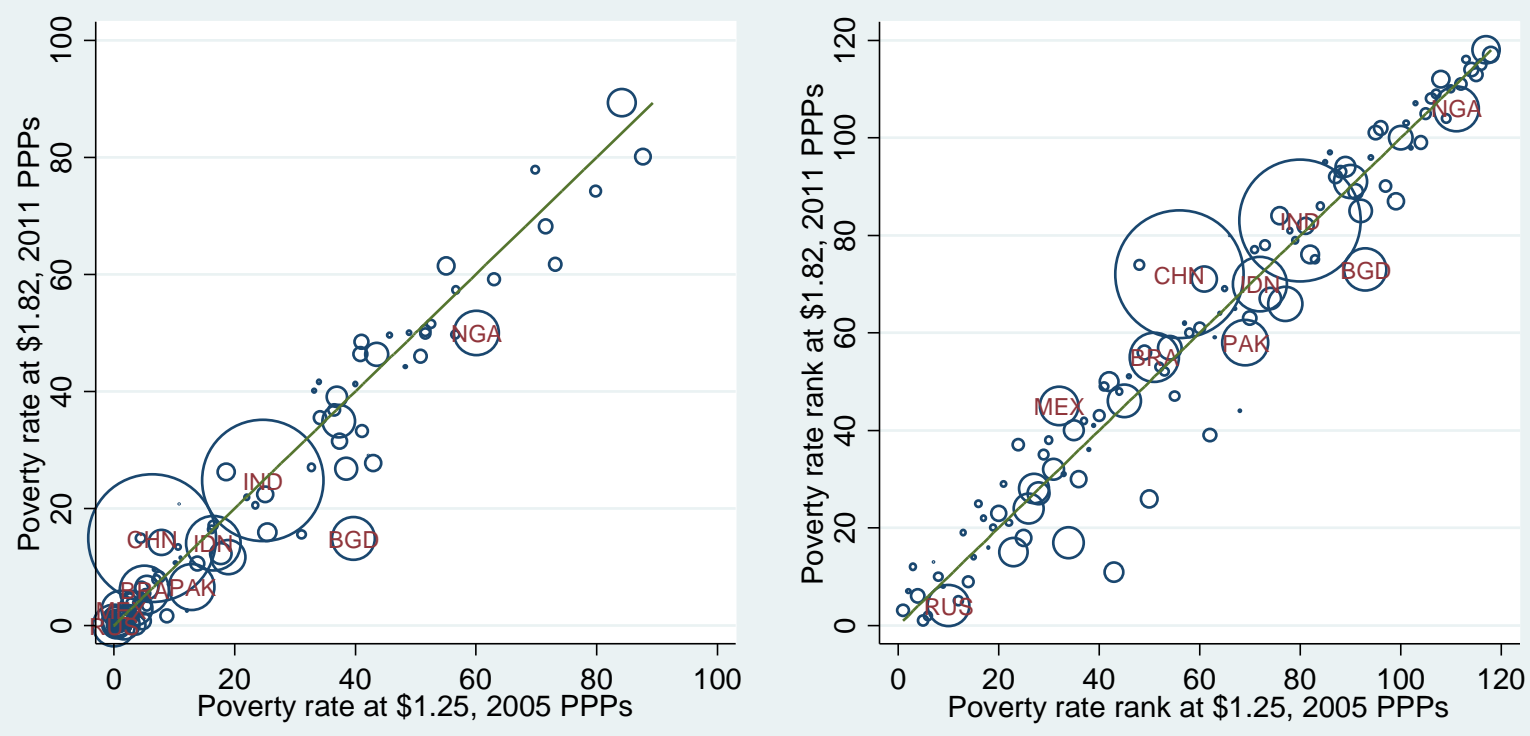

Note: Left panel shows the correlation between country-level headcount rates and right-hand panel shows rank correlation. The size of the marker reflects the size of the population. 
Figure 4: Absolute Deviation of Poverty Rates at the Country level

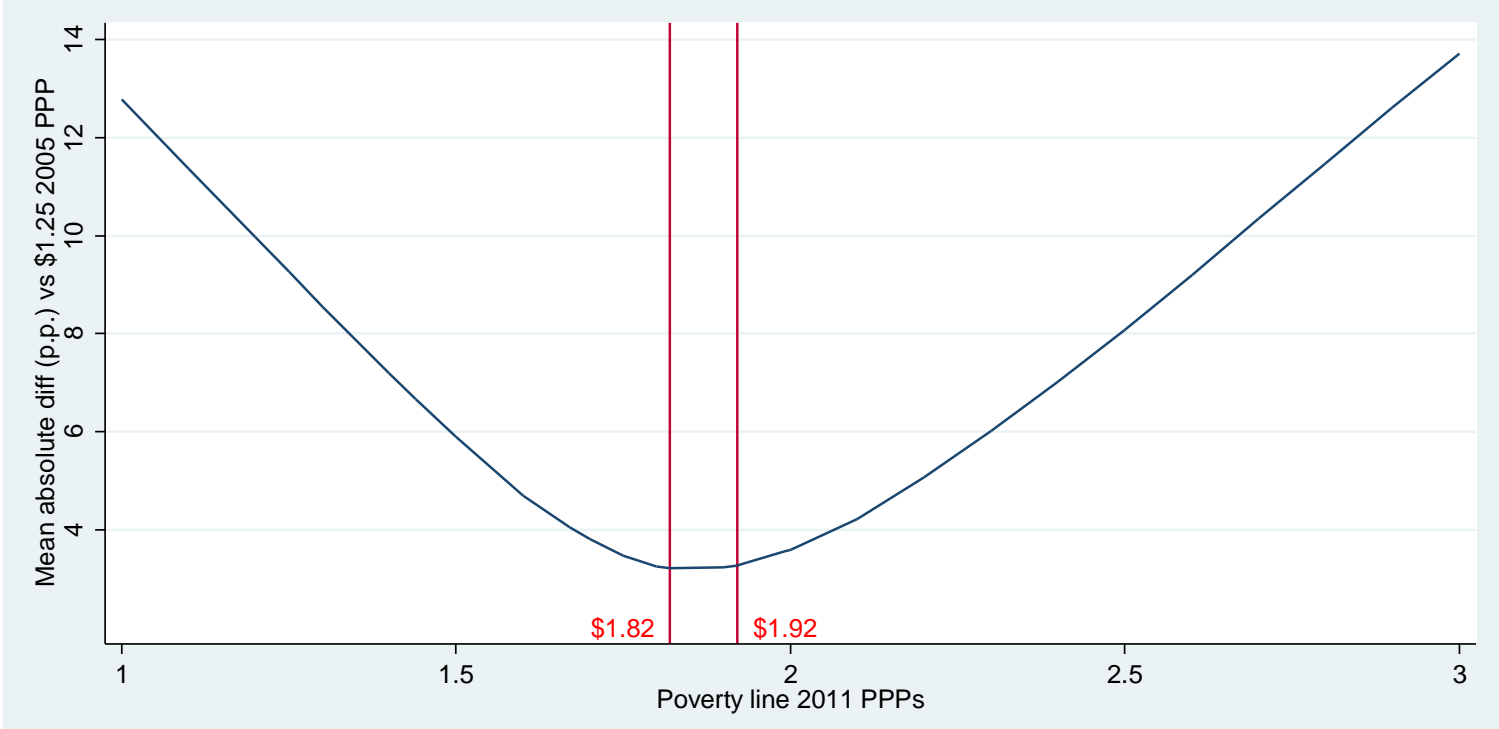

Note: The curve depicts the mean value of the absolute difference in (percentage points) poverty rates at the country level between the \$1.25 line in 2005 PPPs (vertical axis) and poverty rates at various poverty lines in 2011 PPPs (horizontal axis). The mean absolute difference in countrylevel poverty rates is minimized with a poverty line at around \$1.85 per day. 
Figure 5: Changes to poverty in countries with most poor people

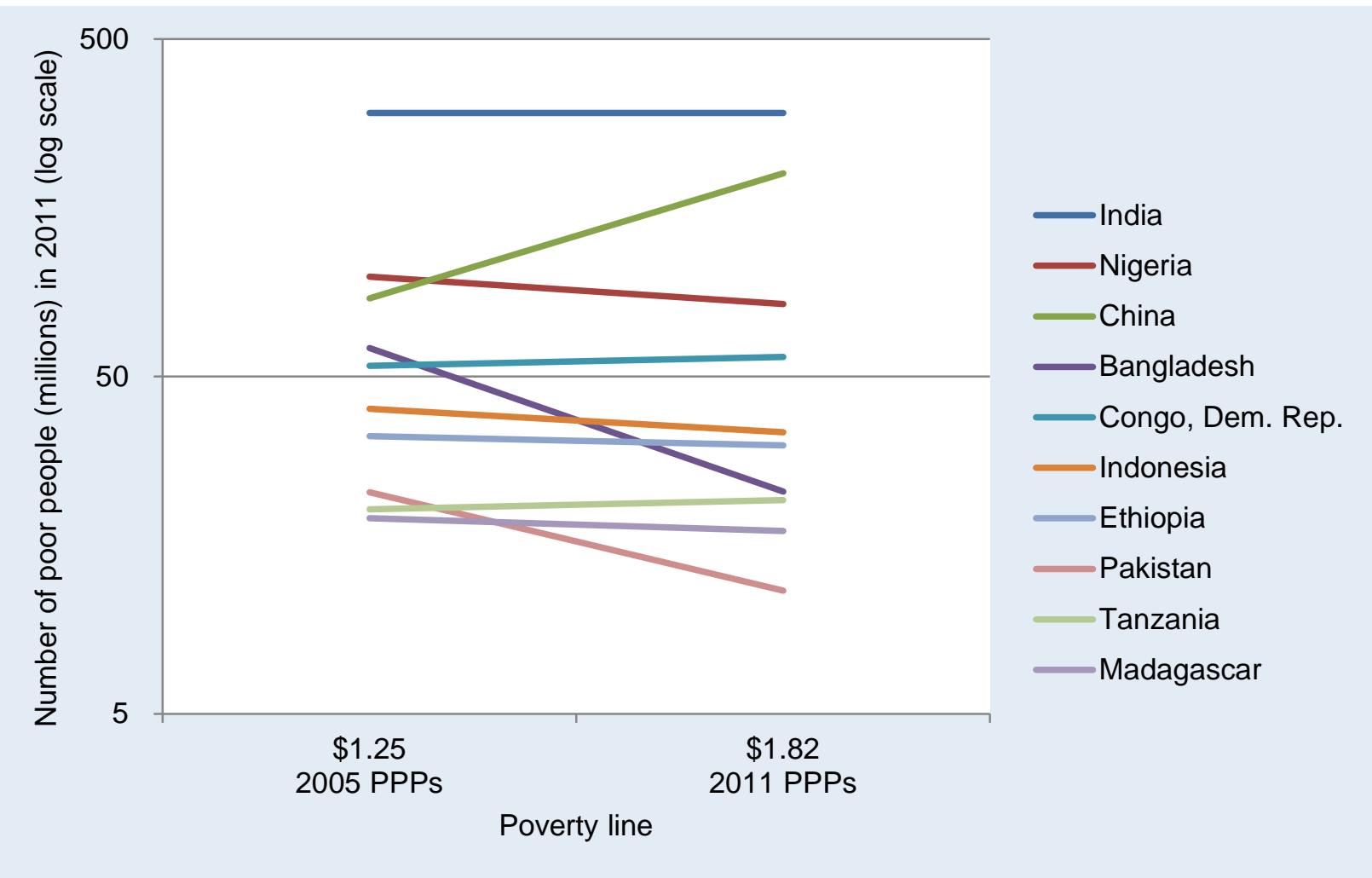

Note: The selected 10 countries in this figure are those with the highest poverty headcount in 2011 (as assessed with the $\$ 1.25$ poverty line and the 2005 PPPs), The figure illustrates how the number of poor changes when moving from the 2005 PPP with the \$1.25 line to the 2011 PPP with the $\$ 1.82$ line. 
Figure 6: Revisions in poverty estimates from 1993 to 2005 PPPs
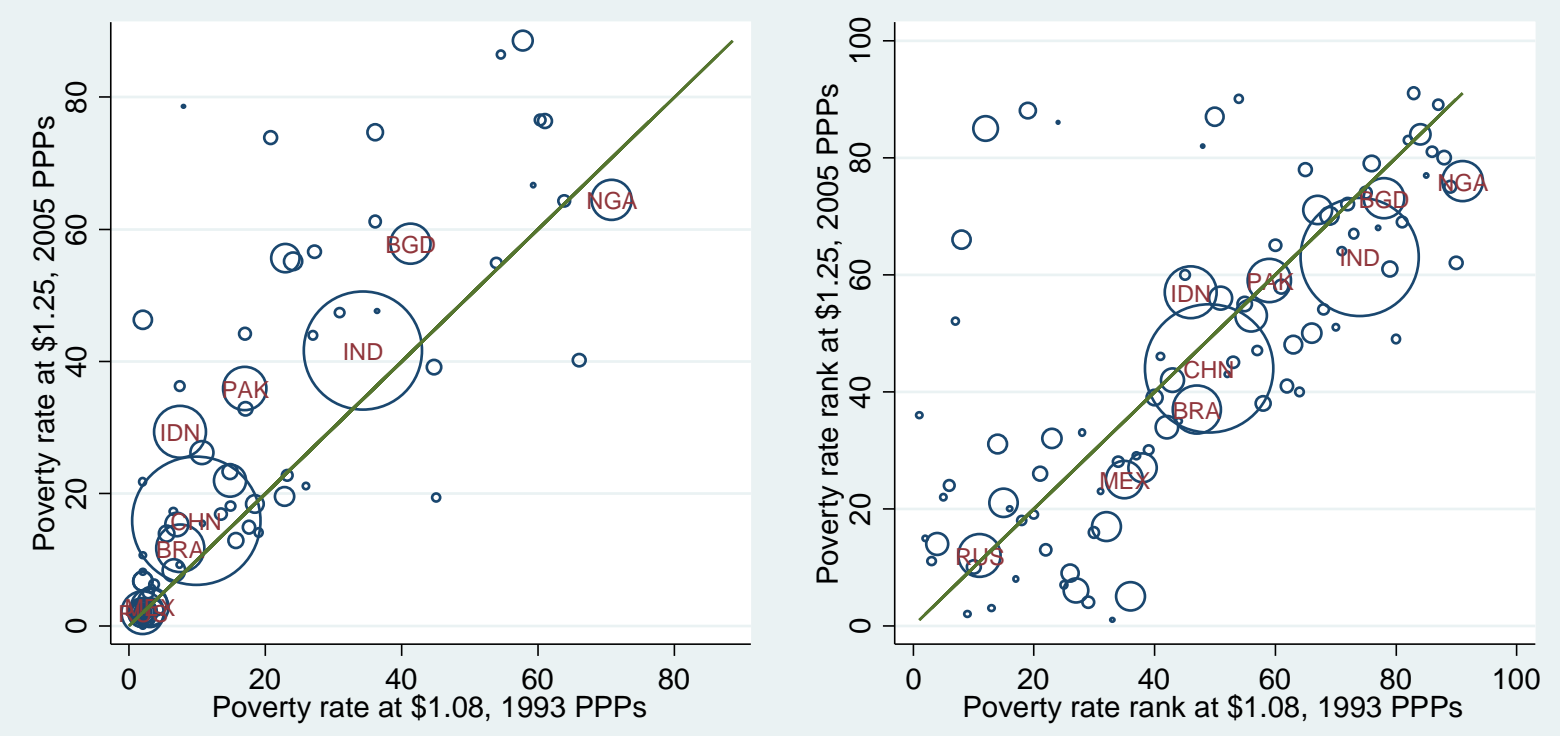

Note: Left panel shows the correlation between country-level headcount rates as measured by comparing the \$1.08 poverty line and the 1993 PPPs (used and reported in the WDI until 2007), with the estimate using the $\$ 1.25$ line and the 2005 PPPs (introduced in 2008 in the WDI). Similar to Figure 3, the right-hand panel shows rank correlation. The size of the marker reflects the size of the population. 
Figure 7: Historic trajectory and poverty projections towards 2030

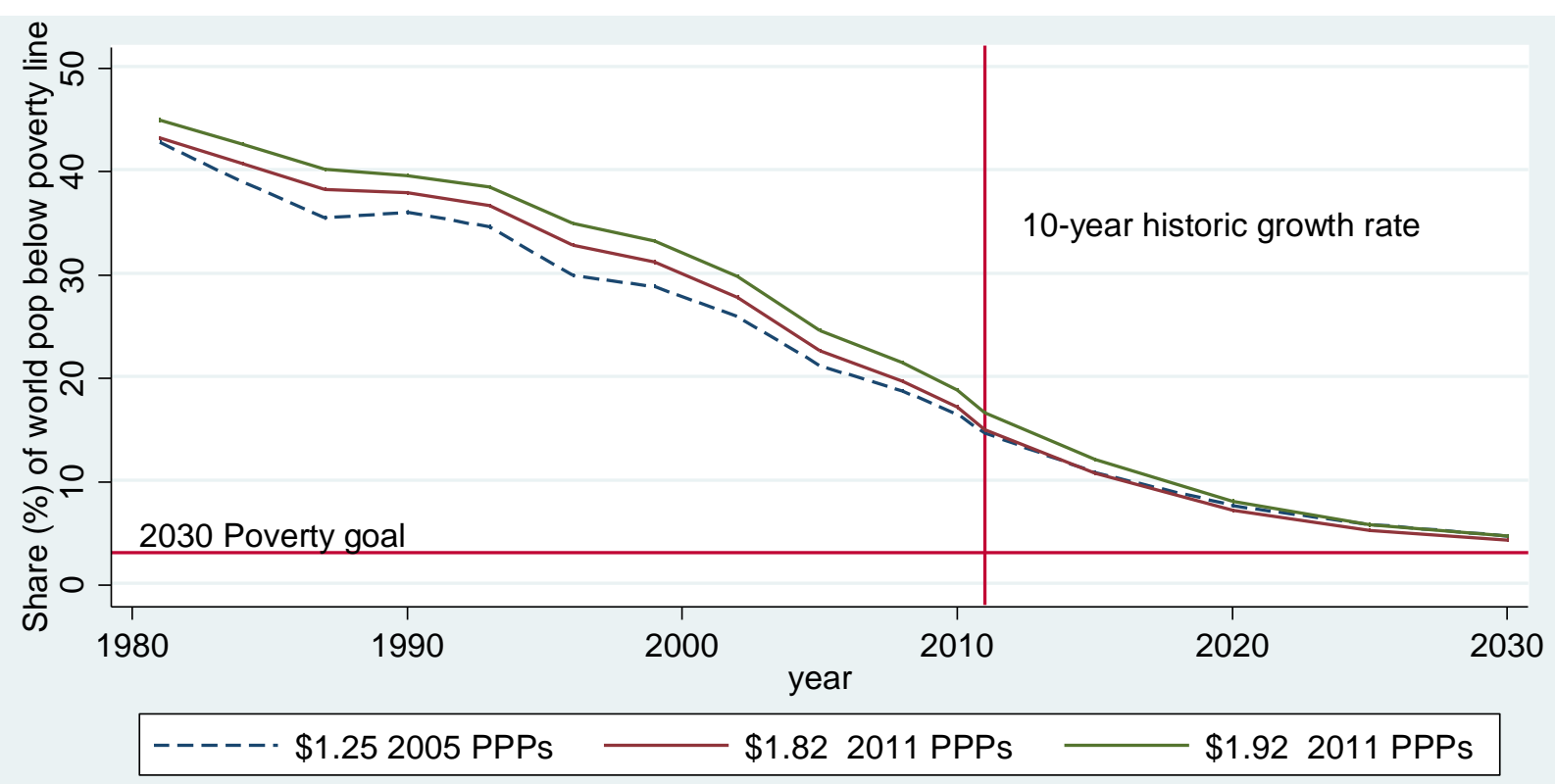

Note: Back-casts and forecasts for \$1.25 poverty line (and 2005 PPP data), \$1.82 line (and 2011 PPP data), and \$1.92 line (and 2011 PPP data). Projections based on country-specific, 10-year historic growth rates. See Jolliffe et al. (2014) for details. 
Figure 8: Projections to 2030 under different average growth scenarios
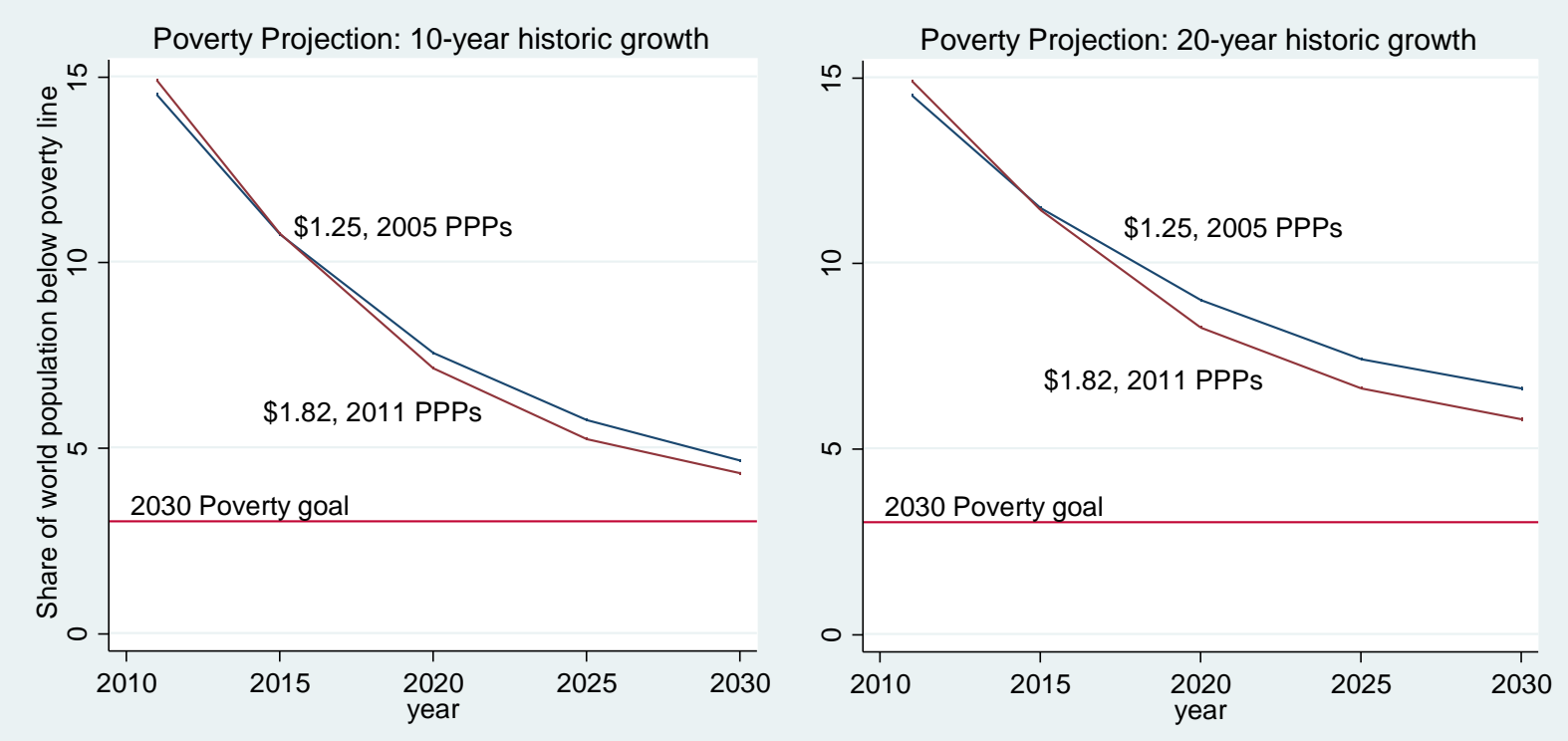

Note: Forecasts for \$1.25 poverty line (and 2005 PPP data) and \$1.82 line (and 2011 PPP data) based on country-specific, 10- and 20-year historic growth rates. See Jolliffe et al. (2014) for details. 
Figure 9: Poverty rates in 2011 and 2030 for poverty lines in 2011 PPPs

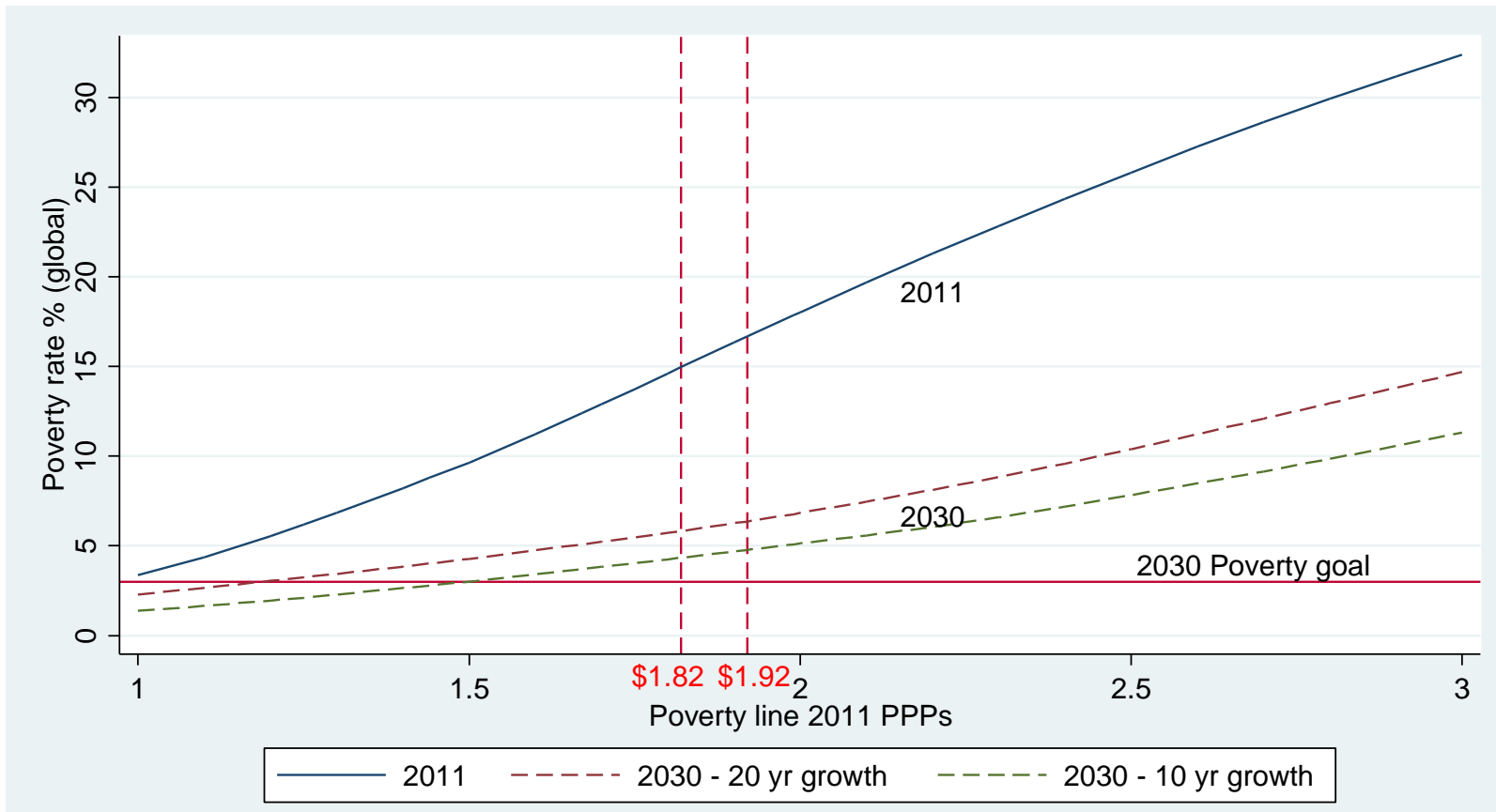

Note: The three upward sloping lines reflect estimated global poverty rates over a set of poverty lines ranging from $\$ 1.00$ to $\$ 3.00$. The highest line is estimated poverty in 2011. The two dashed lines are forecasted poverty in 2030 based on 10- and 20-year average historic growth rates. 


\section{Annex 1: Data and methodology used with PovcalNet data}

\section{A. Data used to generate income distributions and estimate poverty}

As the basis for this paper we use consumption and income distributions that are 'linedup' to the reference years from PovcalNet. These are the same distributions that forms the basis for global poverty monitoring by the World Bank at regular intervals. For easy analysis and application of PPPs and different poverty lines, we follow an approach similar to that of Lakner, Negre and Prydz (2014), using a fitted lognormal Lorenz curve to generate a distribution of 1,000 points for each survey available in PovcalNet, the on-line tool for poverty measurement developed by the Development Research Group of the World Bank, available at http://iresearch.worldbank.org/PovcalNet/. application of a parametric Lorenz curve is very similar to what is done in PovcalNet to calculate poverty when microdata are not directly available, which is the case for more than two-thirds of the surveys provided by the database.

Specifically, we use decile shares and distribution means from PovcalNet and apply the “ungroup” command available through the DASP Stata Package (Abdelkrim and Duclos, 2007) to fit a separate lognormal Lorenz curve for each survey, fitting the decile shares provided in Povcal. This command implements the Shorrocks and Wan (2008) approach which ensure that the fitted Lorenz curve matches the observed shares. The results differ very slightly from PovcalNet with 90 percent of country-level poverty estimates at $\$ 1.25$ per day being within $+/-1$ percentage point 50 percent +/- 0.3 percentage points. The differences between the estimates from PovcalNet and those used in this paper are largest for countries where PovcalNet relies on microdata for estimating poverty (mostly LAC region). The figure below shows the estimates for 2011 compared. The table compares regional estimates. 
Table A1.1: Comparing \$1.25 poverty rates (2005 PPPs) used in this paper with PovcalNet

\begin{tabular}{lrr}
\hline Region & $\begin{array}{r}\text { 2011 Poverty } \\
\text { rate this paper }\end{array}$ & $\begin{array}{r}\text { 2011 Poverty rate } \\
\text { PovcalNet }\end{array}$ \\
\hline East Asia \& Pacific & 8.0 & 7.9 \\
Europe \& Central Asia & 0.9 & 0.5 \\
Latin America \& Caribbean & 5.1 & 4.6 \\
Middle East \& North Africa & 1.7 & 1.7 \\
South Asia & 24.6 & 24.5 \\
Sub-Saharan Africa & 46.9 & 46.8 \\
Global & $\mathbf{1 4 . 5}$ & $\mathbf{1 4 . 5}$ \\
\hline
\end{tabular}

Figure A1.1 Comparing 2005 poverty rates used in this paper with PovcalNet

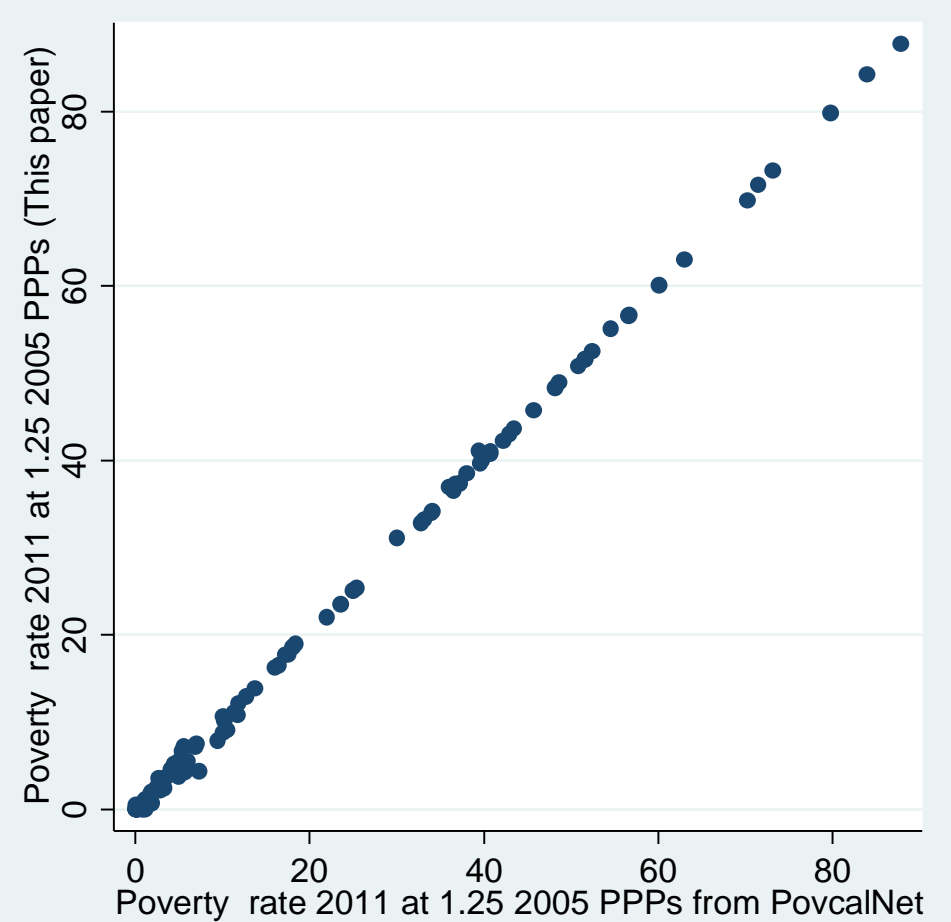




\section{B. Converting PovcalNet consumption and income values from 2005 to 2011 PPPs}

Our method for converting 2005 PPP values to 2011 PPPs follows a method consistent with Chen and Ravallion (2010) and PovcalNet's method for applying the 2005 PPPs. Chen and Ravallion (2010) expresses survey data in the prices of the ICP base year (2005), and then converted to 2005 PPP USD. For surveys in PovcalNet, the 2005 PPP-adjusted USD is given as:

(1) $P P P 05$ inc $_{t}=\frac{\frac{L C U i n c_{t}}{C P I_{t} / C P I_{05}}}{P P P 05}$

where LCUinc is the nominal local currency value recorded in the survey, and $C P I_{t}$ is the CPI (for year t). PPP05 is the 2005 PPP conversion factor for private consumption available from the 2005 ICP. In other words, the LCU value is deflated to the benchmark year and converted with the PPP conversion factor for the base year. Similarly, 2011 PPP-adjusted USD can be defined as:

(2) $P P P 11$ inc $_{t}=\frac{\frac{L C U i n c_{t}}{C P I_{t} / C P I_{11}}}{P P P 11}$

Solving PPP05inc for LCUinc and then substituting into PPP11inc, we get:

(3) $P P P 11$ inc $_{t}=P P P 05$ inc $_{t} \times \frac{C P I_{11}}{C P I_{05}} \times \frac{P P P 05}{P P P 11}$

In other words, to convert PovcalNet values to 2011 PPPs, we convert the 2005 PPP USD values to local currency units for 2005, then apply the CPI (available in PovcalNet) between 2005 and 2011 to convert LCU values from 2005 to 2011 prices, and then finally apply the 2011 PPP conversion factors to obtain values in 2011 PPP USD. ${ }^{35}$

\footnotetext{
${ }^{35}$ When the CPI series in PovcalNet between 2005 and 2011 is incomplete, we use the CPI from WDI to extend the series. A previous version of this paper relied solely on the CPIs available in WDI.
} 


\section{Removing rural-urban adjustments for India, China and Indonesia}

Income distributions derived in 2005 PPPs from PovcalNet contain implicit adjustments for several countries, including China, India and Indonesia, as described in Chen and Ravallion (2010). The PPP conversion factors used for these three countries are described in Table A1.2.

Table A1.2: PovcalNet 2005 PPP conversion factors for urban bias adjustment

\begin{tabular}{lrrrrr}
\hline Country & $\begin{array}{r}\text { Official } \\
\text { PPP }\end{array}$ & $\begin{array}{r}\text { Adjusted } \\
\text { Urban PPP }\end{array}$ & $\begin{array}{r}\text { Adjusted } \\
\text { Rural PPP }\end{array}$ & $\begin{array}{r}\text { Ratio Adjusted } \\
\text { Urban/Official }\end{array}$ & $\begin{array}{r}\text { Ratio Adjusted } \\
\text { Rural/Official }\end{array}$ \\
\hline China & 4.09 & 4.09 & 2.98 & 1.00 & 0.73 \\
India & 15.6 & 17.24 & 11.4 & 1.11 & 0.73 \\
Indonesia & 4192 & 4795.9 & 3399.7 & 1.14 & 0.81 \\
\hline
\end{tabular}

For these three countries, we undo the adjustments when applying the 2011 PPPs by adding an additional factor of the ratio of the adjusted to official PPP (two last columns of Table A1.2) to equation (3) to get:

(4) $P P P 11$ inc $_{t}=P P P 05$ inc $_{t} \times \frac{P P P 05_{\text {adj }}}{P P P 05_{\text {unad }}} \times \frac{C P I_{11}}{C P I_{05}} \times \frac{P P P 05}{P P P 11}$

The resulting estimate of the national distributions and associated poverty measures are equivalent to what we would obtain if the rural and urban distributions denominated in national currencies were converted using the national official PPP conversion factors at face value, without any adjustments. When we apply this method for 'un-adjusting' the PovcalNet data, we obtain national poverty estimates that are in line with the estimates without rural-urban adjustments to the application of PPPs reported by Chen and Ravallion (2008) for China. 